\title{
Thoracic and cardiovascular surgery in Japan during 2015
}

\author{
Annual report by The Japanese Association for Thoracic Surgery
}

\begin{abstract}
Committee for Scientific Affairs, The Japanese Association for Thoracic Surgery - Munetaka Masuda ${ }^{2}$. Shunsuke Endo $^{3}$ - Shoji Natsugoe ${ }^{4}$ Hideyuki Shimizu $^{5} \cdot$ Yuichiro Doki $^{6} \cdot$ Yasutaka Hirata $^{7}$. Junjiro Kobayashi $^{8} \cdot$ Noboru Motomura $^{9} \cdot$ Kiyoharu Nakano $^{10} \cdot$ Hiroshi Nishida $^{11} \cdot$ Morihito Okada $^{12}$. Yoshikatsu Saiki $^{13} \cdot$ Aya Saito $^{14} \cdot$ Yukio Sato $^{1} \cdot$ Kazuo Tanemoto $^{15} \cdot$ Yasushi Toh $^{16} \cdot$ Hiroyuki Tsukihara $^{17}$. Shinji Wakui ${ }^{18} \cdot$ Hiroyasu Yokomise ${ }^{19} \cdot$ Kohei Yokoi $^{20} \cdot$ Yutaka Okita $^{21}$
\end{abstract}

The Japanese Association for Thoracic Surgery has conducted annual surveys of thoracic surgery throughout Japan since 1986 to determine the statistics regarding the number of procedures according to operative category. Here, we have summarized the results from our annual survey of thoracic surgery performed during 2015.

As has been done so far, thoracic surgery was classified into three categories - cardiovascular, general thoracic, and esophageal surgery - and the patient data were examined and analyzed for each group. Access to the computerized data is offered to all members of this Association. We honor and value all member's continued professional support and contributions (Tables 1,2).

The incidence of hospital mortality was added to the survey to determine the nationwide status, which has contributed to the Japanese surgeons to understand the present status of thoracic surgery in Japan and to make progress to improve operative results by comparing their work with those of others. The Association was able to gain a better understanding of present problems as well as future prospects, which has been reflected to its activity including education of its members.

Thirty-day mortality (so-called "operative mortality") is defined as death within 30 days of operation regardless of the patient's geographic location and even after the patient had been discharged from the hospital. Hospital mortality is defined as death within any time interval after an operation if the patient had not been discharged from the hospital.

Annual report by The Japanese Association for Thoracic Surgery: Committee for Scientific Affair.

S. Endo and S. Natsugoe equally contributed.

Extended author information available on the last page of the article
Hospital-to-hospital transfer in the categories of esophageal surgery is not considered discharge: transfer to a nursing home or a rehabilitation unit is considered hospital discharge unless the patient subsequently dies of complications of the operation. On the contrary, hospital-to-hospital transfer after 30 days of operation in the categories of cardiovascular surgery and general thoracic surgery is considered discharge because data of national clinical database (NCD) 2015 were used in this category and hospital-to-hospital transfer after 30 days of operation is considered discharge in NCD.

\section{Abstract of the survey}

All data regarding cardiovascular surgery and thoracic surgery were obtained from NCD, whereas data regarding esophageal surgery were collected from survey questionnaire by The Japanese Association for Thoracic Surgery forms because NCD of esophageal surgery does not include non-surgical cases (i.e., patients with adjuvant chemotherapy or radiation alone). Based on the change in data aggregation, there are several differences between this 2015 annual report and previous annual reports: the number of institutions decreased in each category from 578 (2014) to 568 (2015) in cardiovascular, from 762 to 714 in general thoracic and from 626 to 571 in esophageal surgery. Because more than two departments in the same institute registered their data to NCD individually, we cannot calculate correct number of institutes in this survey. Then, the response rate is not indicated in the category of cardiovascular surgery (Table 1), and the number of institutions classified by the operation number is also not 
Table 1 Questionnaires sent out and received back by the end of December 2015

\begin{tabular}{llll}
\hline & Sent out & Returned & Response rate \\
\hline (A) Cardiovascular surgery & - & 568 & - \\
(B) General thoracic surgery & 736 & 714 & $97.0 \%$ \\
(C) Esophageal surgery & 610 & 571 & $93.6 \%$ \\
\hline
\end{tabular}

Table 2 Categories subclassified according to the number of operations performed

\begin{tabular}{lc}
\hline Number of operations performed & $\begin{array}{l}\text { Category } \\
\text { General thoracic surgery }\end{array}$ \\
\hline 0 & 12 \\
$1-24$ & 66 \\
$25-49$ & 120 \\
$50-99$ & 190 \\
$100-149$ & 138 \\
$150-199$ & 80 \\
$\geqq 200$ & 108 \\
Total & 714 \\
\hline Number of operations performed & \\
\hline 0 & Esophageal surgery \\
$1-4$ & 81 \\
$5-9$ & 151 \\
$10-19$ & 101 \\
$20-29$ & 102 \\
$30-39$ & 46 \\
$40-49$ & 29 \\
$\geqq 50$ & 13 \\
Total & 48 \\
\hline & 571 \\
\hline &
\end{tabular}

calculated in the category of cardiovascular surgery (Table 2).

\section{Final report}

\section{(A) Cardiovascular surgery}

First, we are very pleased with our colleague's (member's) cooperation to our survey of cardiovascular surgery, which

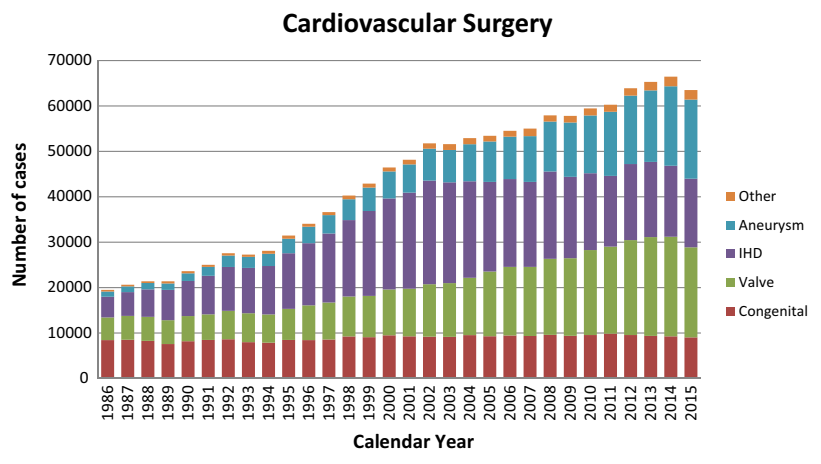

Fig. 1 Cardiovascular surgery, IHD ischemic heart disease

definitely enhances the quality of this annual report. We are truly grateful again for the enormous effort put into completing the NCD at each participating institution.

Figure 1 shows the development of cardiovascular surgery in Japan over the last 29 years. Aneurysm surgery includes only operations for thoracic and thoracoabdominal aortic aneurysm. Extra-anatomic bypass surgery for thoracic aneurysm and pacemaker implantation were totally excluded from the survey since 2015 . The number of assist device implantation operations is not included in the total number of surgical operations, while it remained in the survey. A total of 69,512 cardiovascular operations were performed at 561 institutions during 2015 alone and included 44 heart transplantations, which were re-started in 1999.

The number of operations for congenital heart disease (9054 cases) decreased in 2.3\% compared with that of 2014 (9269 cases) [1], and $2.5 \%$ decrease when compared with the data of 10 years ago (9287 cases in 2005) [2]. The number of operations for adult heart disease $(19,820$ cases in valvular heart disease, 15,103 ischemic heart disease, 17,444 cases in thoracic aortic aneurysm and 1897 cases for other procedures) decreased compared with those of 2014 (9.7, 3.4, 0.3 and $10.4 \%$, respectively).

During the last 10 years, the numbers of operations for adult heart disease increased constantly except for that for ischemic heart disease $39.1 \%$ increase in valvular heart disease, $23.5 \%$ decrease in ischemic heart disease, $101.1 \%$ increase in thoracic aortic aneurysm, and $56.5 \%$ increase in other procedures compared those of 2005 [2]). The concomitant coronary artery bypass grafting procedure (CABG) is not included in ischemic heart disease but included in other categories such as valvular heart disease 


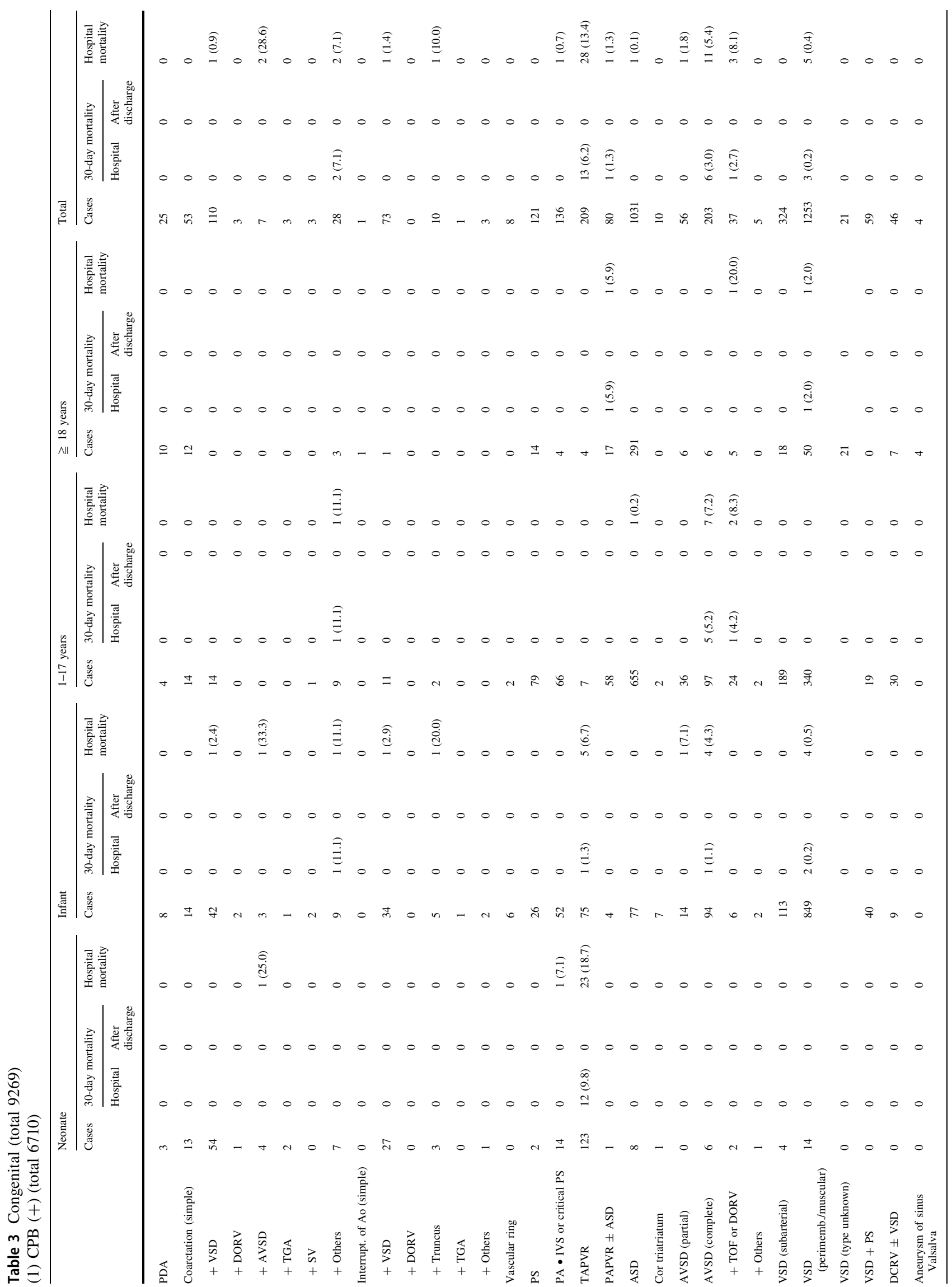


584

General Thoracic and Cardiovascular Surgery (2018) 66:581-615

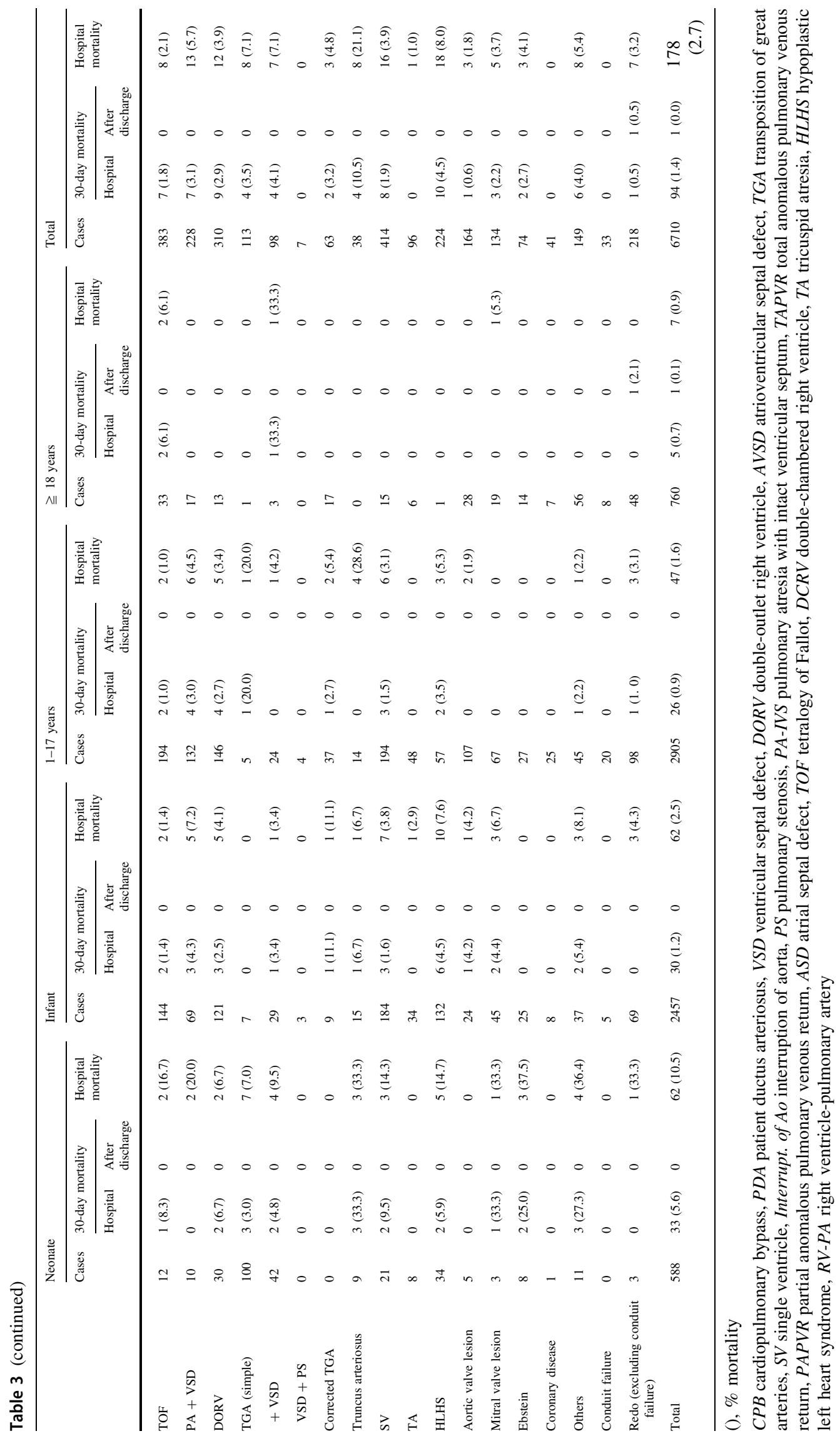

Springer 


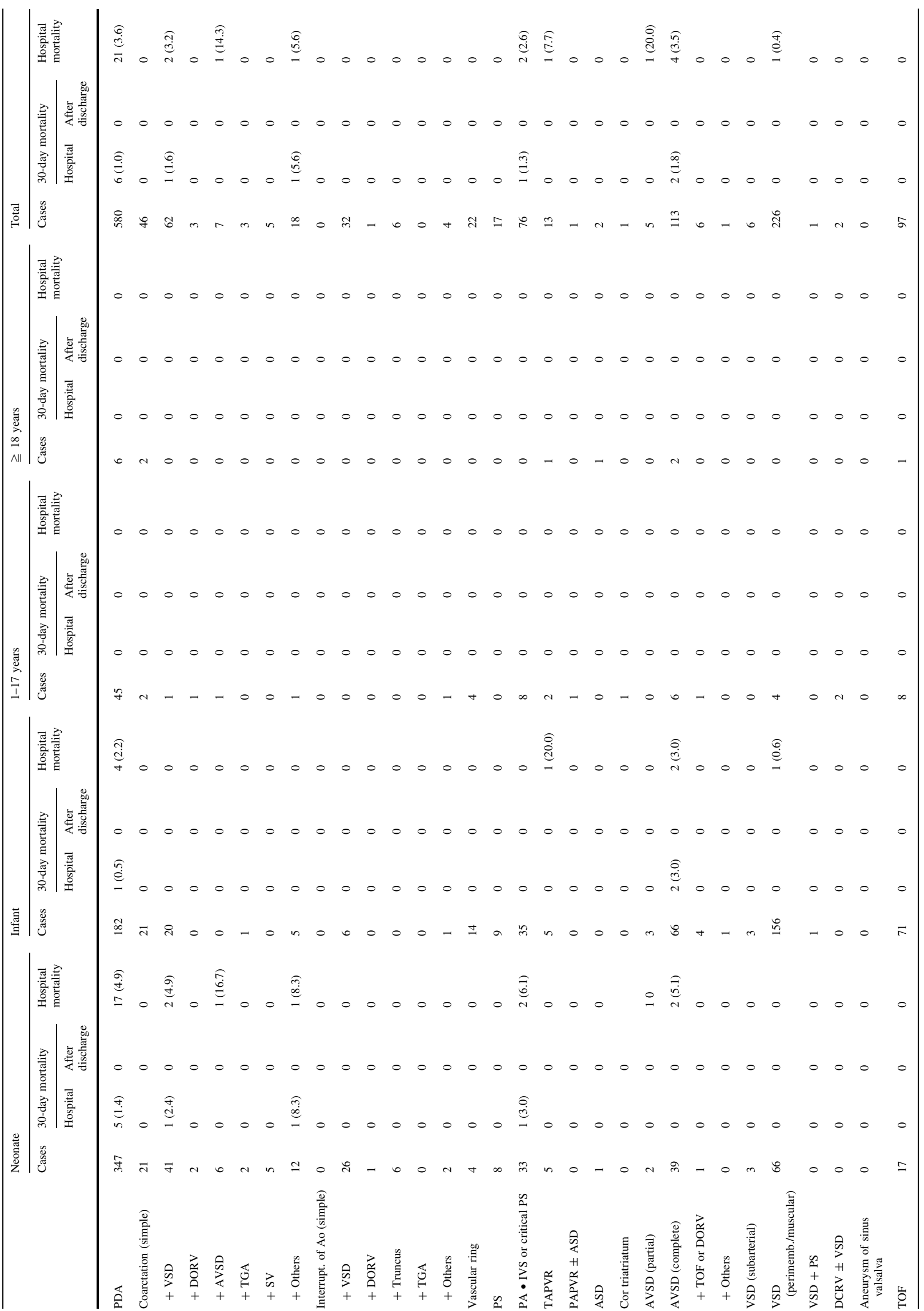


586

General Thoracic and Cardiovascular Surgery (2018) 66:581-615

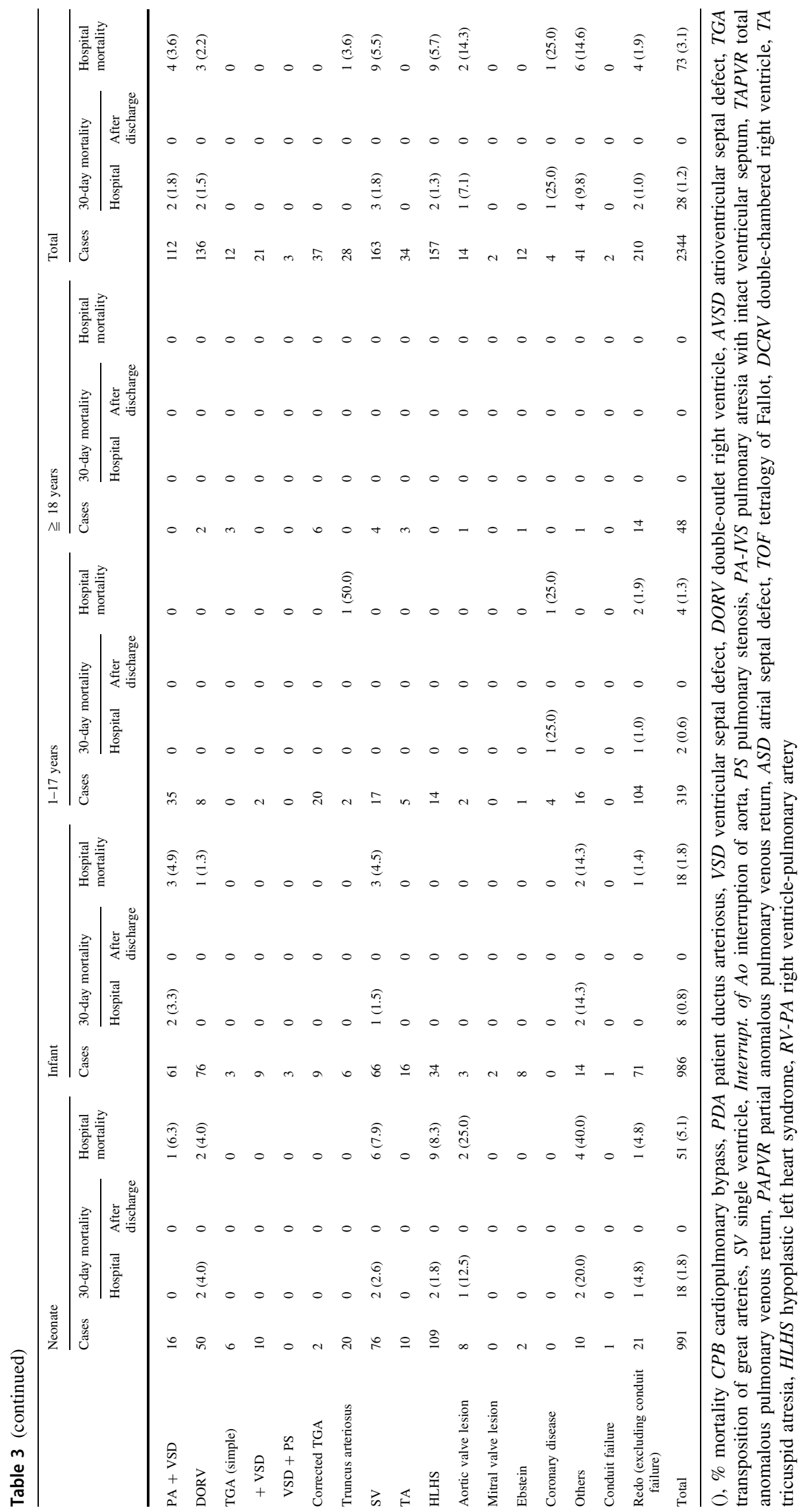

Springer 


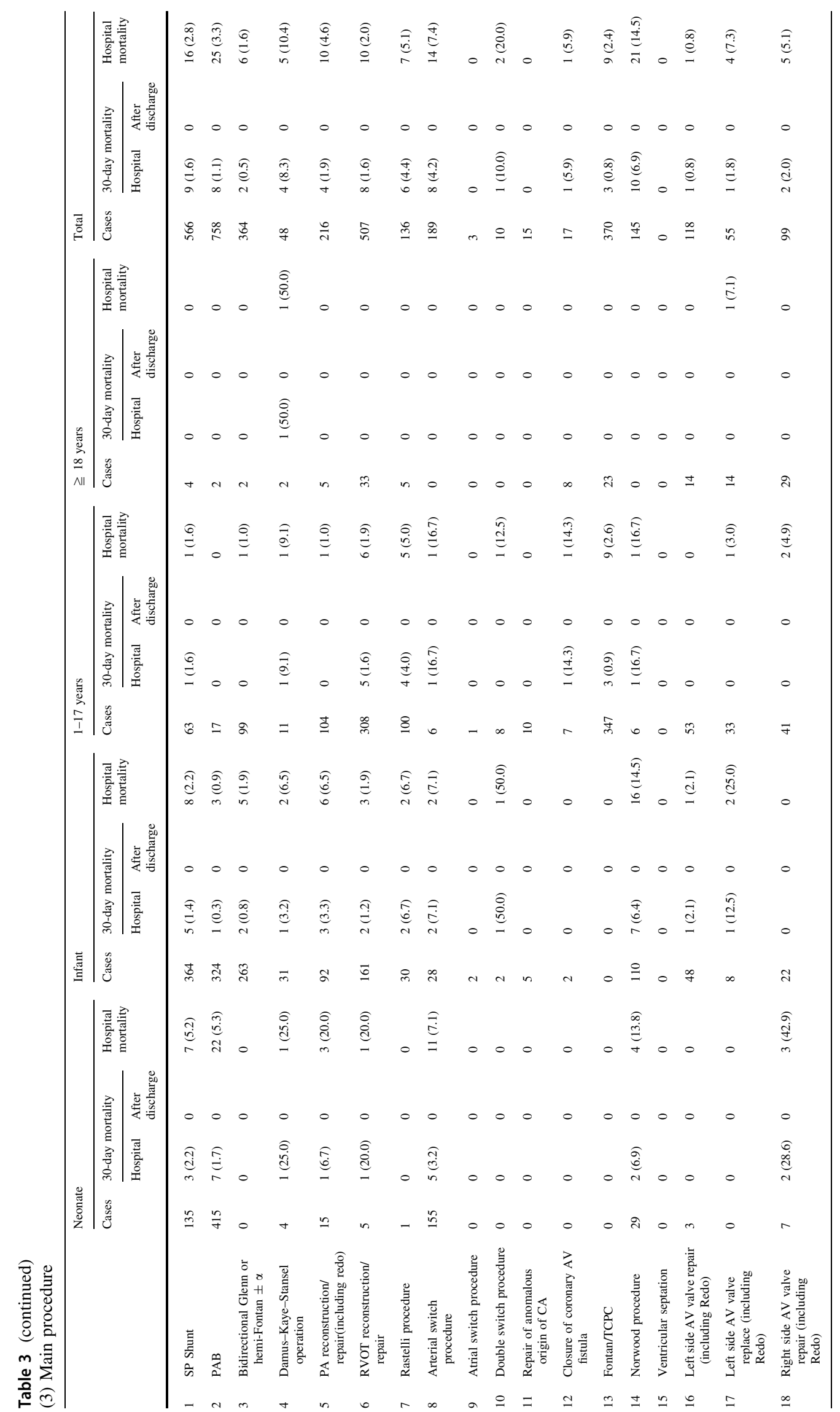


588

General Thoracic and Cardiovascular Surgery (2018) 66:581-615

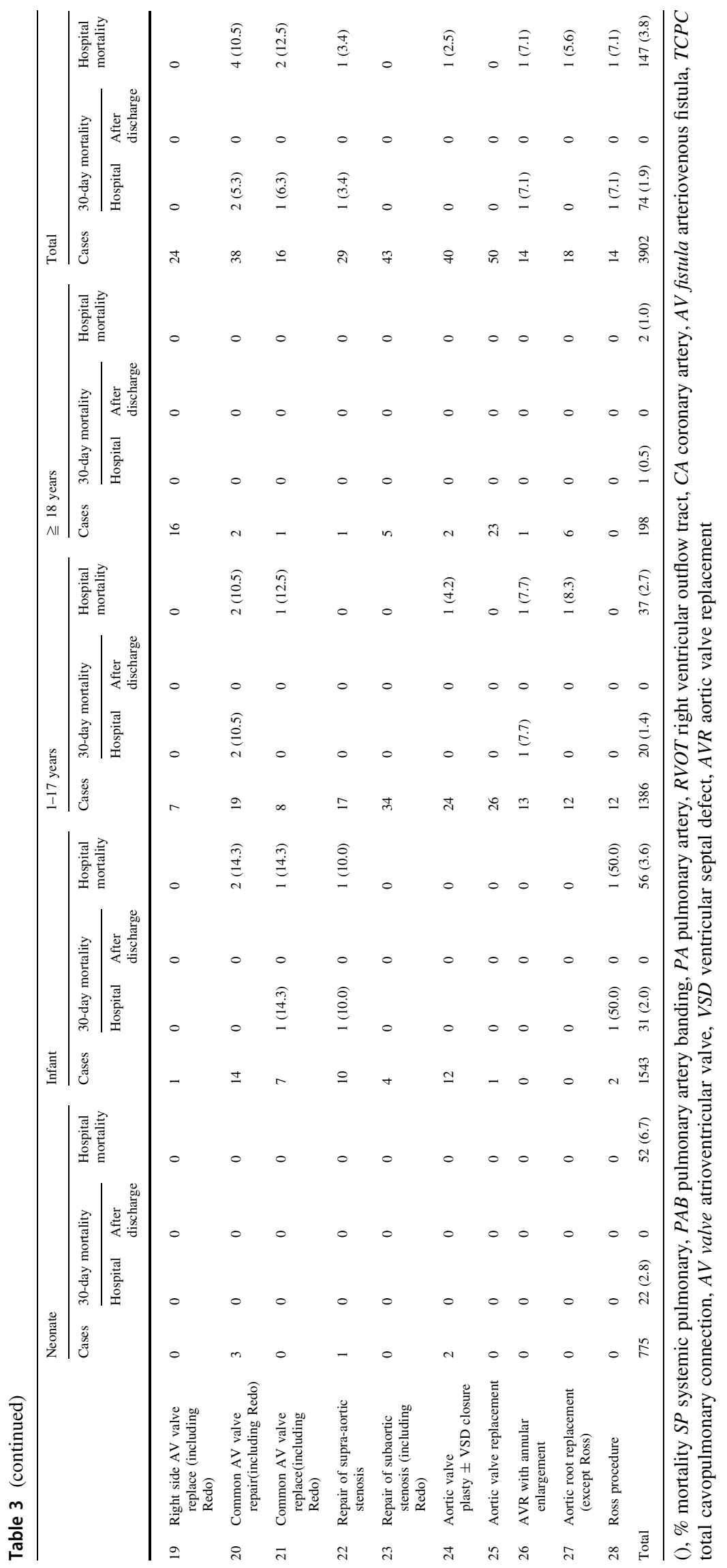

Springer 


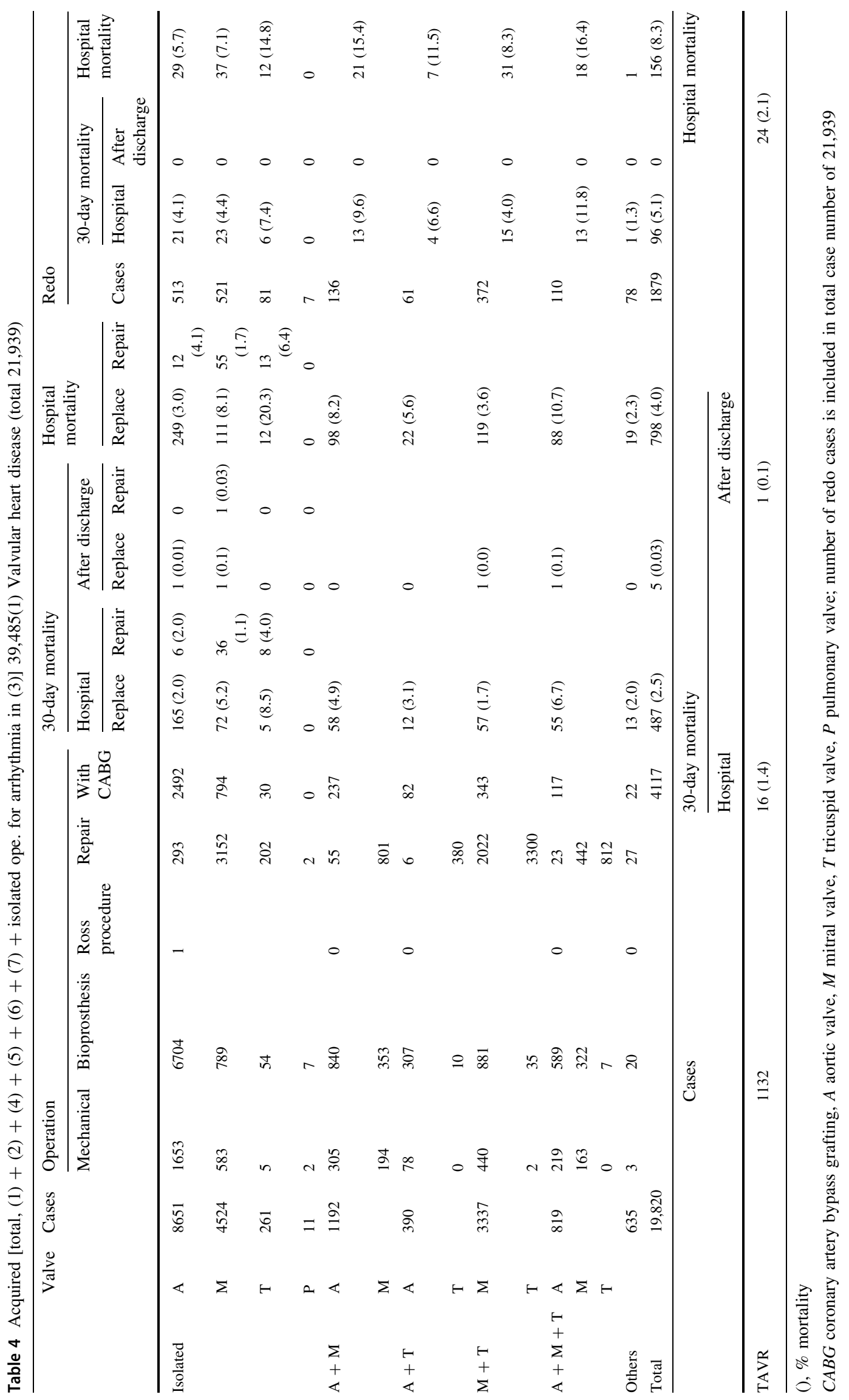




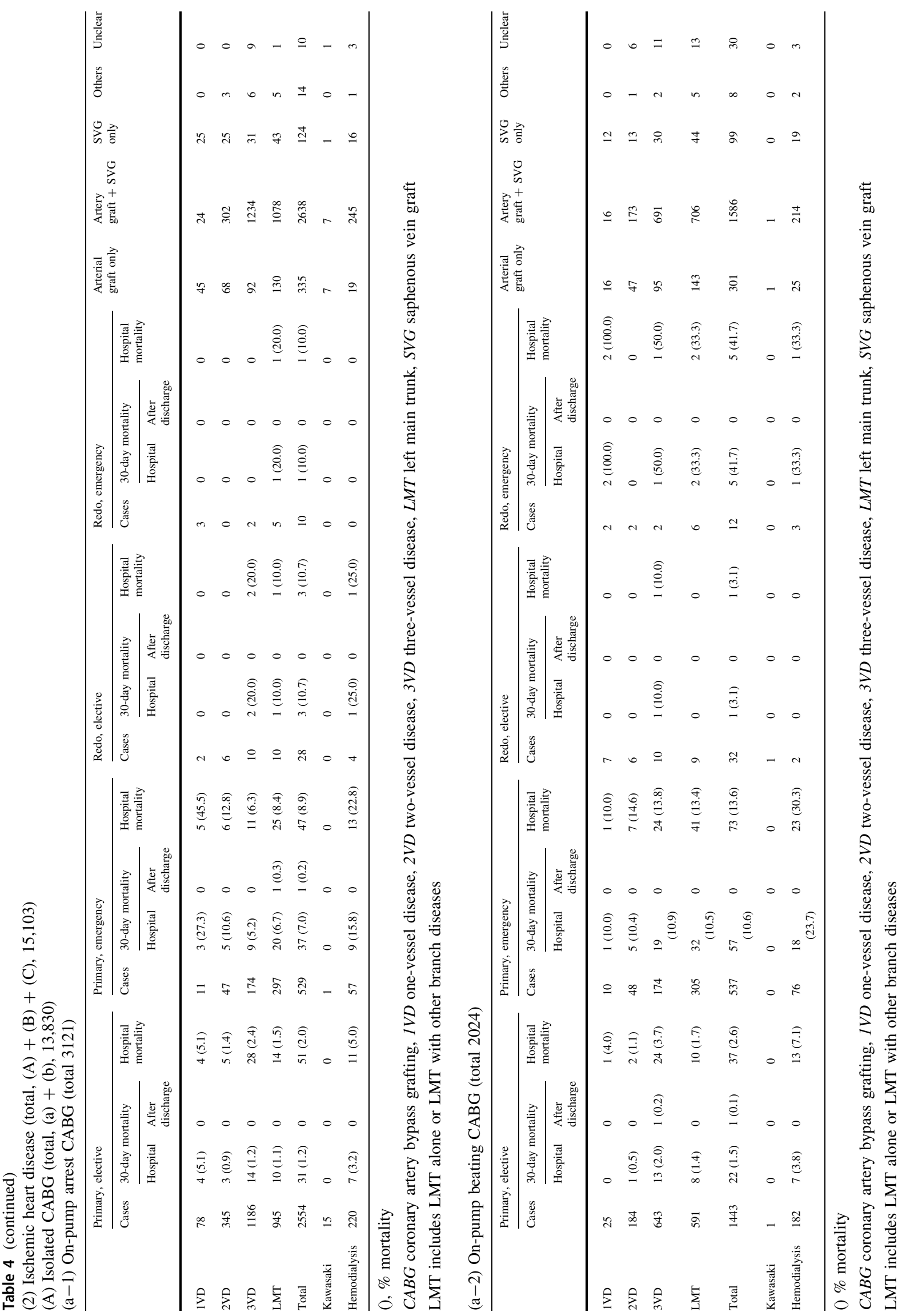



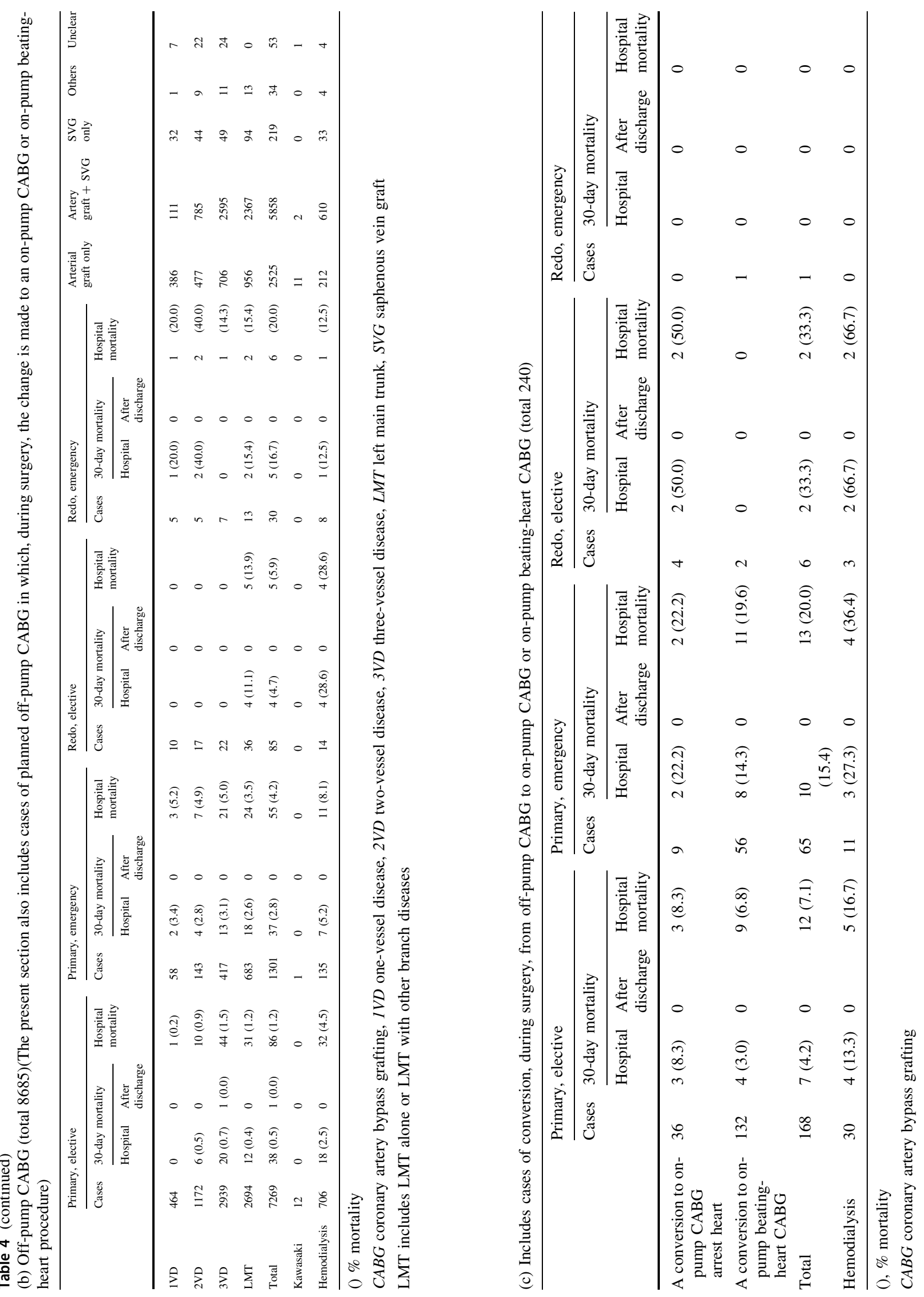


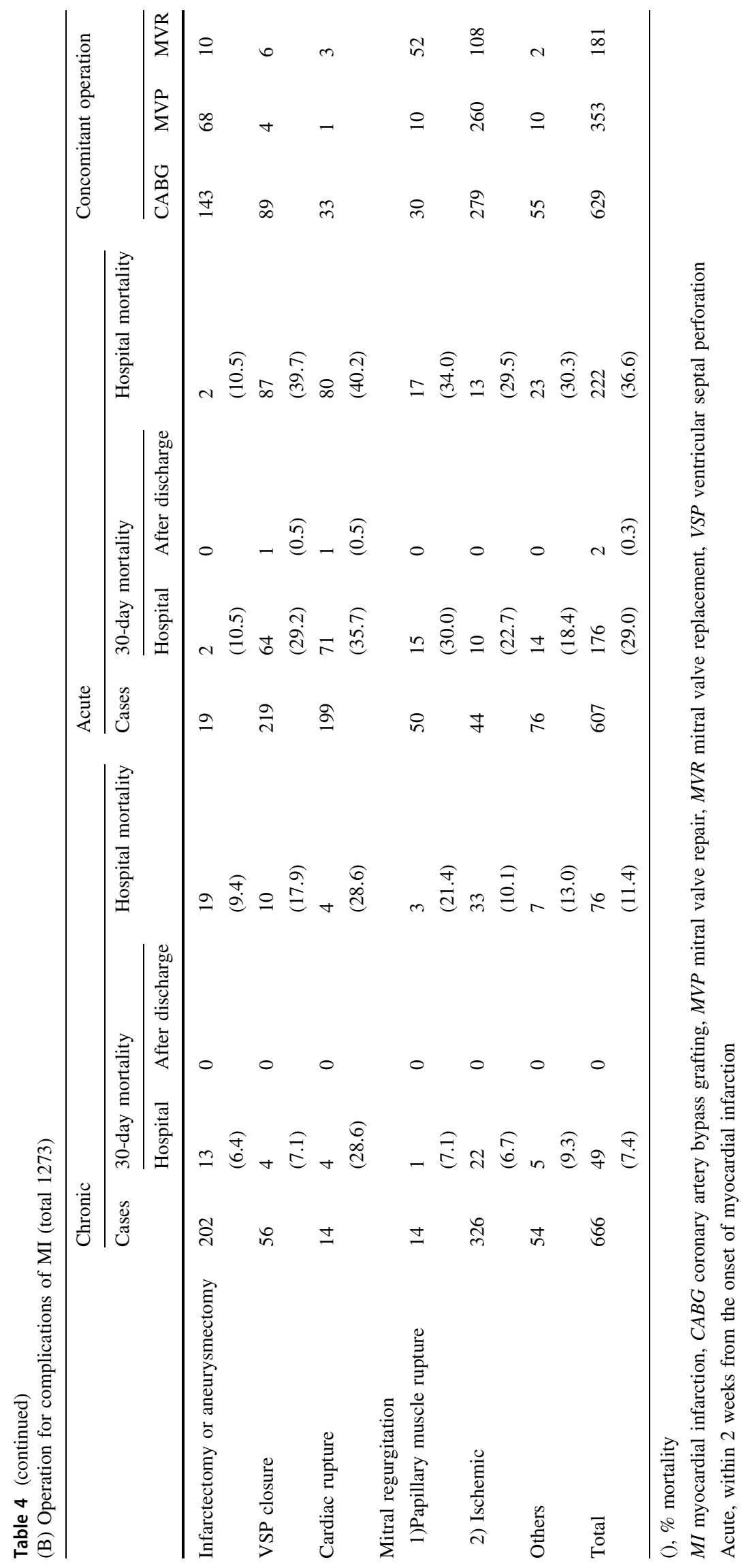


Table 4 (continued)

(C) TMLR (total 0)

\begin{tabular}{lllll}
\hline & Cases & 30 -day mortality & Hospital \\
\cline { 3 - 5 } & & Hospital & After discharge & 0 \\
Isolated & 0 & 0 & 0 & 0 \\
with CABG & 0 & 0 & 0 & 0 \\
Total & 0 & 0 & 0 \\
\hline
\end{tabular}

$T M L R$ transmyocardial laser revascularization

(3) Operation for arrhythmia (total 5765)

\begin{tabular}{|c|c|c|c|c|c|c|c|c|c|c|c|}
\hline & \multirow[t]{3}{*}{ Cases } & \multirow{2}{*}{\multicolumn{2}{|c|}{ 30-day mortality }} & \multirow{3}{*}{$\begin{array}{l}\text { Hospital } \\
\text { mortality }\end{array}$} & \multicolumn{7}{|c|}{ Concomitant operation } \\
\hline & & & & & \multirow[t]{2}{*}{ Isolated } & \multirow[t]{2}{*}{ Congenital } & \multirow[t]{2}{*}{ Valve } & \multirow[t]{2}{*}{ IHD } & \multirow[t]{2}{*}{ Others } & \multicolumn{2}{|c|}{ Multiple combination } \\
\hline & & Hospital & $\begin{array}{l}\text { After } \\
\text { discharge }\end{array}$ & & & & & & & $\begin{array}{l}2 \\
\text { categories }\end{array}$ & $\begin{array}{l}3 \\
\text { categories }\end{array}$ \\
\hline Maze & 3795 & $73(1.9)$ & $1(0.03)$ & $108(2.8)$ & 80 & 180 & 3338 & 607 & 290 & 636 & 49 \\
\hline For WPW & 2 & 0 & 0 & 0 & 0 & 0 & 2 & 0 & 0 & 0 & 0 \\
\hline $\begin{array}{l}\text { For ventricular } \\
\text { tachyarrhythmia }\end{array}$ & 40 & $1(2.5)$ & 0 & $2(5.0)$ & 2 & 0 & 15 & 24 & 8 & 8 & 1 \\
\hline Others & 1928 & $35(1.8)$ & 0 & $68(3.5)$ & 122 & 82 & 1531 & 400 & 214 & 384 & 30 \\
\hline Total & 5765 & $\begin{array}{l}109 \\
(1.9)\end{array}$ & $1(0.02)$ & $178(3.1)$ & 204 & 262 & 4886 & 1031 & 512 & 1028 & 80 \\
\hline
\end{tabular}

() \% mortality

Except for 106 isolated cases, all remaining 3749 cases are doubly allocated, one for this subgroup and the other for the subgroup corresponding to the concomitant operations

WPW Wolff-Parkinson-White syndrome, IHD ischemic heart disease

(4) Operation for constrictive pericarditis (total 184)

\begin{tabular}{|c|c|c|c|c|c|c|c|c|}
\hline & \multicolumn{4}{|c|}{$\mathrm{CPB}(+)$} & \multicolumn{4}{|c|}{$\mathrm{CPB}(-)$} \\
\hline & \multirow[t]{2}{*}{ Cases } & \multicolumn{2}{|c|}{ 30-day mortality } & \multirow[t]{2}{*}{ Hospital mortality } & \multirow[t]{2}{*}{ Cases } & \multicolumn{2}{|c|}{ 30-day mortality } & \multirow[t]{2}{*}{ Hospital mortality } \\
\hline & & Hospital & After discharge & & & Hospital & After discharge & \\
\hline Total & 96 & $10(10.4)$ & 0 & $17(17.7)$ & 88 & $5(5.7)$ & 0 & $7(8.0)$ \\
\hline
\end{tabular}

() \% mortality

$C P B$ cardiopulmonary bypass

(5) Cardiac tumor (total 560)

\begin{tabular}{|c|c|c|c|c|c|c|c|c|}
\hline & \multirow[t]{2}{*}{ Cases } & \multicolumn{2}{|c|}{ 30-day mortality } & \multirow[t]{2}{*}{ Hospital mortality } & \multicolumn{4}{|c|}{ Concomitant operation } \\
\hline & & Hospital & After discharge & & AVR & MVR & CABG & others \\
\hline \multirow[t]{2}{*}{ Benign tumor (cardiac myxoma) } & 465 & $2(0.4)$ & 0 & $6(1.3)$ & 10 & 7 & 32 & 82 \\
\hline & 347 & $1(0.3)$ & 0 & $4(1.2)$ & 8 & 4 & 22 & 53 \\
\hline \multirow[t]{2}{*}{ Malignant tumor (primary) } & 95 & $9(9.5)$ & $1(1.1)$ & $12(12.6)$ & 0 & 3 & 3 & 15 \\
\hline & 29 & $3(10.3)$ & $1(3.4)$ & $3(10.3)$ & 0 & 1 & 2 & 7 \\
\hline
\end{tabular}

(), \% mortality

$A V R$ aortic valve replacement, $M V R$ mitral valve replacement, $C A B G$ coronary artery bypass grafting 
Table 4 (continued)

(6) HOCM and DCM (total 304)

\begin{tabular}{|c|c|c|c|c|c|c|c|c|}
\hline & \multirow[t]{2}{*}{ Cases } & \multicolumn{2}{|c|}{ 30-day mortality } & \multirow[t]{2}{*}{ Hospital mortality } & \multicolumn{4}{|c|}{ Concomitant operation } \\
\hline & & Hospital & After discharge & & AVR & MVR & MVP & CABG \\
\hline Myectomy & 139 & $\begin{array}{l}6 \\
(4.3)\end{array}$ & 0 & $\begin{array}{l}10 \\
(7.2)\end{array}$ & 73 & 33 & 16 & 20 \\
\hline Myotomy & 4 & 0 & 0 & 0 & 1 & 0 & 1 & 1 \\
\hline No resection & 144 & $\begin{array}{l}7 \\
(4.9)\end{array}$ & 0 & $\begin{array}{l}15 \\
(10.4)\end{array}$ & 27 & 63 & 81 & 16 \\
\hline Volume reduction surgery of the left ventricle & 17 & 0 & 0 & $\begin{array}{l}2 \\
(11.8)\end{array}$ & 0 & 1 & 13 & 4 \\
\hline Total & 304 & $\begin{array}{l}13 \\
(4.3)\end{array}$ & 0 & $\begin{array}{l}27 \\
(8.9)\end{array}$ & 101 & 97 & 111 & 41 \\
\hline
\end{tabular}

(), \% mortality

$H O C M$ hypertrophic obstructive cardiomyopathy, $D C M$ dilated cardiomyopathy, $A V R$ aortic valve replacement, $M V R$ mitral valve replacement, $M V P$ mitral valve repair, $C A B G$ coronary artery bypass grafting

(7) Other open-heart operation (total 669)

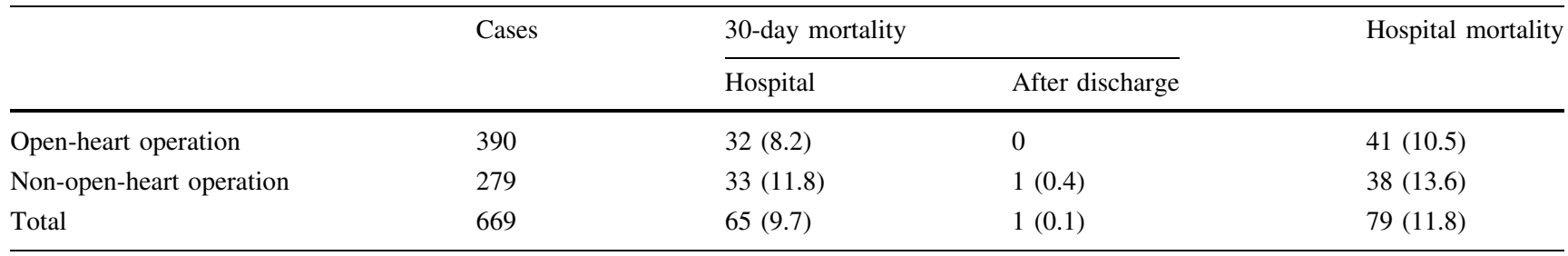

(), \% mortality

and thoracic aneurysm in our study, then, the number of CABG still remained over 20,000 cases per year $(20,785$ cases) in 2015. Data for individual categories are summarized in Tables 3, 4, 5, 6, 7, 8 and 9.

In 2015, 6894 open-heart operations for congenital heart disease were performed with overall hospital mortality of $2.7 \%$. The number of operations for congenital heart disease decreased gradually throughout these 10 years (maximum 7386 cases in 2006), and overall hospital mortality showed plateau around $3.0 \%$. In detail, the most common disease was ventricular septal defect (1253 cases), for the first time since the inauguration of this survey. Atrial septal defect (ASD), which had been the most common disease, was the "second" common one (1031 cases) in 2015. It was mainly due to the development of catheter device for ASD closure commercially available in Japan since 2005. In the last 10 years, hospital mortality for complex congenital heart disease was as follows (2005 [2], 2010 [3], and 2015): complete atrio-septal defect (4.7, 4.2 and 1.7\%), tetralogy of Fallot (1.6, 0.8 and 1.3\%), transposition of the great arteries with intact septum $(6.2,4.1$ and 6.6\%) and with ventricular septal defect (15.9, 7.3 and 3.9\%), single ventricle (5.3, 7.5 and 4.3\%), and hypoplastic left heart syndrome $(24.4,13.1$ and 9.8\%). Right heart bypass surgery is now commonly performed (364 bidirectional Glenn procedures excluding 48 Damus-Kaye-Stansel procedures and 370 Fontan type procedures including total cavopulmonary connection) with acceptable hospital mortality (1.6 and $2.4 \%$ ). Norwood type I procedure was performed in 145 cases with relatively low hospital mortality rate of $14.5 \%$.

The number of operations for valvular heart disease has constantly increased until 2014 (21,939 cases) [1], and that was 19,820 cases in 2015 . The hospital mortality of primary single valve placement was 2.8 and $8.7 \%$ for the aortic and the mitral position, while that for primary mitral valve repair was $1.7 \%$. Hospital mortality rate for redo valve surgery was $5.7 \%$ in aortic and $7.1 \%$ in mitral positions, respectively. Finally, overall hospital mortality did not show dramatic improvement during the last 10 years (3.6\% in 2005 [2], $3.1 \%$ in 2010 [3], and $4.0 \%$ in 2015), which might be partially due to the recent progression of age of the patients. Repair of the valve became a popular procedure (377 cases in the aortic, 6417 cases in the mitral, and 4942 cases in the tricuspid), and mitral valve repair constituted $32.4 \%$ of all valvular operations and $65.0 \%$ of all mitral valve procedures, which are similar to those of the last 5 years. Aortic and mitral valve 


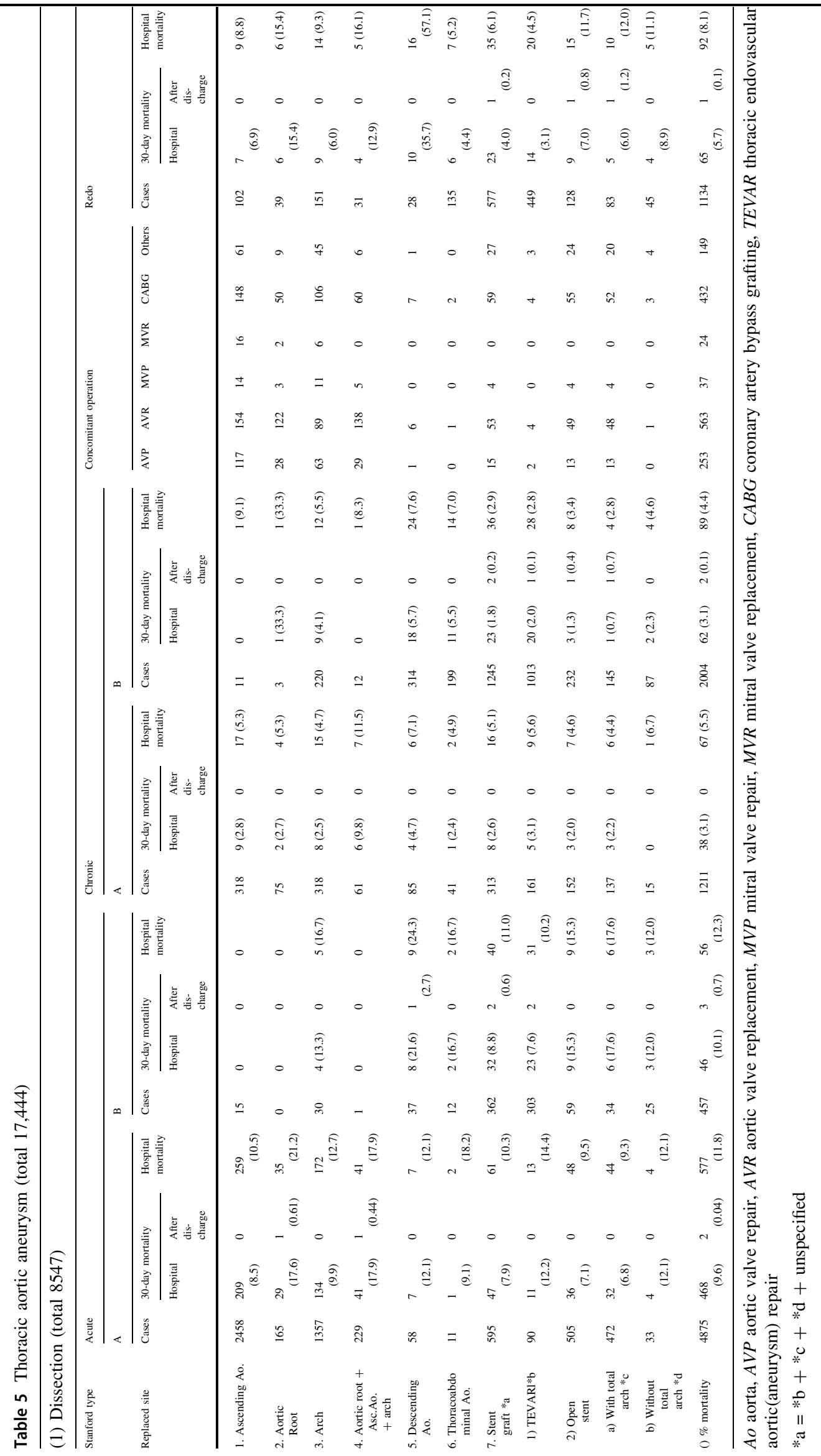




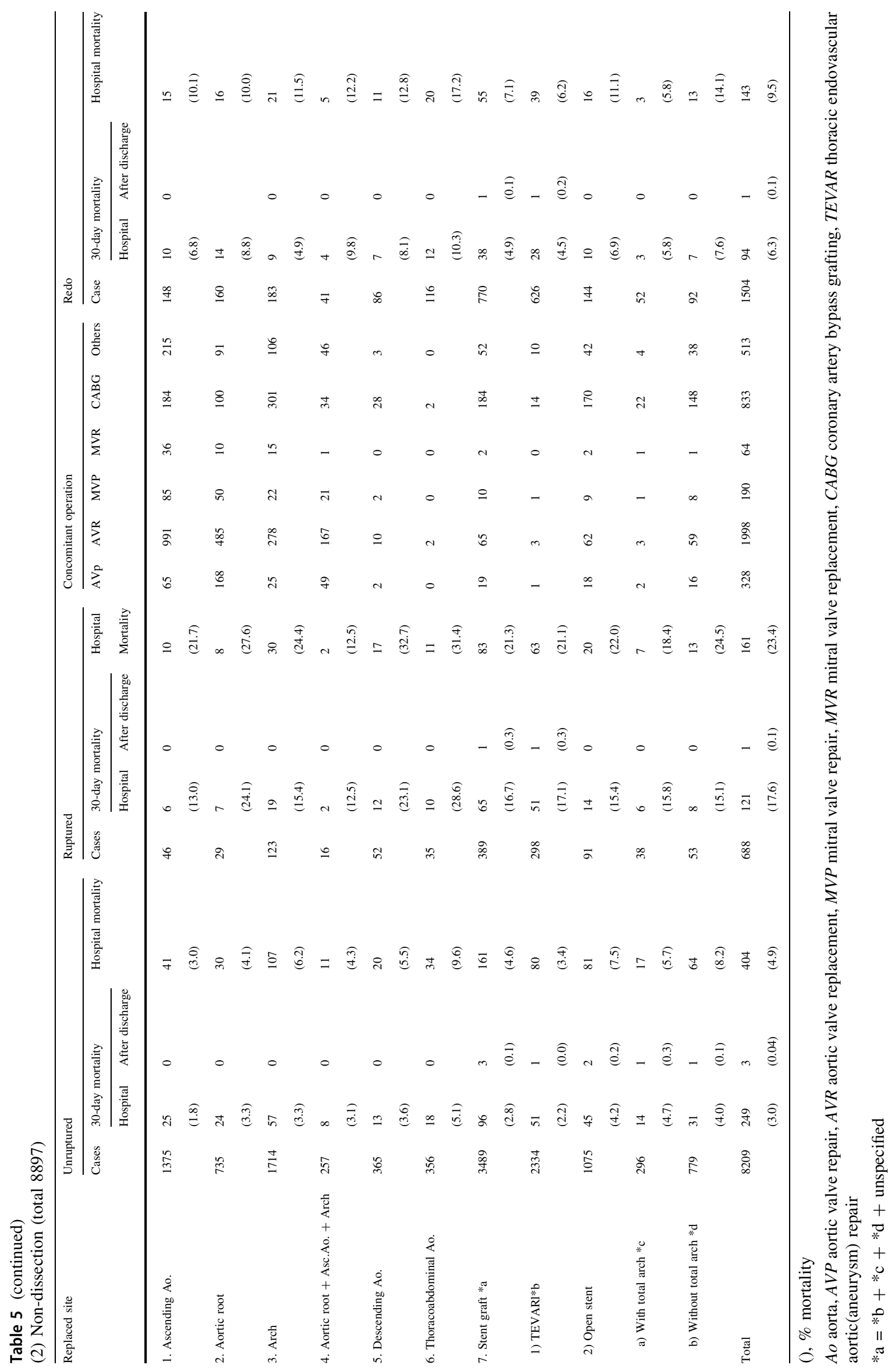


Table 6 Pulmonary thromboembolism (total 134)

\begin{tabular}{lllll}
\hline & Cases & \multicolumn{2}{l}{30 -day mortality } & Hospital mortality \\
\cline { 3 - 4 } & & Hospital & After discharge & \\
\hline Acute & 75 & $18(24.0)$ & 0 & $19(25.3)$ \\
Chronic & 59 & 0 & 0 & 0 \\
Total & 134 & $18(13.4)$ & 0 & $19(14.2)$ \\
\hline
\end{tabular}

( ), \% mortality

replacements with bioprosthesis were performed in 6704 cases and 789 cases, respectively. The ratio of bioprosthesis was $76.4 \%$ at the aortic and $23.8 \%$ at the mitral position. This ratio of the aortic bioprosthesis increased dramatically from 30 to $40 \%$ in the early 2000 s $[4,5]$ to more than $70 \%$ recent 5 years. CABG as a concomitant procedure was performed in $20.8 \%$ of operations for all valvular heart disease (14.4\% in 2005 [2] and $17.3 \%$ in 2010 [3]).

Isolated CABG was performed in 13,830 cases which were only $75.4 \%$ of that of 10 years ago (2005 [2]). Among these, off-pump CABG was intended in 8685 cases $(63.0 \%)$ with a success rate of $97.2 \%$, so final success rate of off-pump CABG was $61.1 \%$. The percentage of intended off-pump CABG reached $60.3 \%$ in 2004 [4] and then was kept over $60 \%$ until now. In 13,830 isolated CABG patients, $96.8 \%$ of them received at least one arterial graft, while all arterial graft CABGs were performed only in $22.9 \%$ of them. The operative and hospital mortality rates associated with primary elective CABG procedures in 11,266 cases were 0.8 and $1.5 \%$, respectively. Similar data analysis of CABG including primary/redo and elective/emergency data was begun in 2003 [5], and the operative and hospital mortality rates associated with primary elective CABG procedures in 2003 were 1.0 and $1.5 \%$, respectively, so operative results of primary CABG have been stable. Hospital mortality of primary emergency CABG in 2367 cases was still high and was $7.4 \%$. The result of conversion from off-pump CABG rate was $2.8 \%$ and hospital mortality in that was $11.3 \%$. A total of 1273 patients underwent surgery for complications of myocardial infarction, including 272 operations for left ventricular aneurysm, ventricular septal perforation or cardiac rupture and 340 operations for ischemic mitral regurgitation.

Operations for arrhythmia were performed mainly as a concomitant procedure in 5765 cases associated with $49.5 \%$ increase comparing with that of 2014. The hospital mortality of arrhythmia surgery including 3795 MAZE procedures was $3.1 \%$. MAZE procedure has become quite popular procedure (2497 cases in 2005 [2] and 3591 cases in 2010 [3]).

Operations for thoracic aortic dissection were performed in 8691 cases and this increased by $12.4 \%$ this year compared with those of last year. For 6575 Stanford type A acute aortic dissections, hospital mortality remained high and was $9.9 \%$. Operations for a non-dissected thoracic

Table 7 Assisted circulation (total 1637)

\begin{tabular}{|c|c|c|c|c|c|c|c|c|c|c|c|c|c|c|c|}
\hline \multirow[t]{4}{*}{ Sites } & \multicolumn{9}{|l|}{ VAD } & \multicolumn{6}{|c|}{ Heart-lung assist } \\
\hline & \multicolumn{3}{|l|}{ Device } & \multicolumn{6}{|c|}{ Results } & \multicolumn{2}{|c|}{ Method } & \multicolumn{4}{|l|}{ Results } \\
\hline & \multirow[t]{2}{*}{ Centrifugal } & \multirow{2}{*}{$\begin{array}{l}\text { VAS } \\
\text { (extra) }\end{array}$} & \multirow{2}{*}{$\begin{array}{l}\text { VAS } \\
\text { (implant) }\end{array}$} & \multicolumn{3}{|c|}{ Not weaned } & \multicolumn{3}{|c|}{ Weaned } & \multirow[t]{2}{*}{ PCPS } & \multirow[t]{2}{*}{ Others } & \multicolumn{2}{|c|}{ Not weaned } & \multicolumn{2}{|l|}{ Weaned } \\
\hline & & & & $\begin{array}{l}\text { On } \\
\text { going }\end{array}$ & Death & Transplant & Alive & Deaths & Transplant & & & Deaths & Transplant & Deaths & Alive \\
\hline \multicolumn{16}{|c|}{ Post-cardiotomy } \\
\hline Left & 13 & 4 & 2 & 3 & $9(47.4)$ & 0 & 12 & $4(21.1)$ & 0 & & & & & & \\
\hline Right & 8 & 0 & 0 & 0 & $2(25.0)$ & 0 & 5 & 1 & 0 & & & & & & \\
\hline \multicolumn{16}{|l|}{ Biventricle } \\
\hline Right & 4 & 0 & 0 & 0 & $3(75.0)$ & 0 & 1 & $0(0.0)$ & 0 & 485 & 99 & & 0 & & 228 \\
\hline Left & 2 & 2 & 0 & & & & & & & & & (46.1) & & (14.9) & \\
\hline \multicolumn{16}{|c|}{ Congestive heart failure } \\
\hline Left & 61 & 37 & 135 & 131 & $\begin{array}{l}57 \\
\quad(24.5)\end{array}$ & 1 & 41 & $15(6.4)$ & 2 & & & & & & \\
\hline Right & 4 & 0 & 0 & 1 & $0(0.0)$ & 0 & 2 & $0(0.0)$ & 1 & & & & & & \\
\hline \multicolumn{16}{|l|}{ Biventricle } \\
\hline Right & 24 & 10 & 2 & 8 & & 0 & 7 & $2(5.6)$ & 1 & 624 & 30 & & 2 & & 236 \\
\hline Left & 17 & 19 & 0 & & $(50.0)$ & & & & & & & (49.8) & & (13.8) & \\
\hline $\begin{array}{l}\text { Respiratory } \\
\text { failure }\end{array}$ & & & & & & & & & & 80 & 40 & $\begin{array}{l}35 \\
\quad(29.2)\end{array}$ & 0 & $\begin{array}{l}16 \\
\quad(13.3)\end{array}$ & 44 \\
\hline Total & 133 & 72 & 139 & 143 & $\begin{array}{l}89 \\
\quad(25.9)\end{array}$ & 1 & 68 & $22(6.4)$ & 4 & 1189 & 169 & $\begin{array}{l}630 \\
(46.4)\end{array}$ & 2 & $\begin{array}{l}193 \\
(14.2)\end{array}$ & 508 \\
\hline
\end{tabular}

( ), \% mortality 
Table 8 Heart transplantation (total 44)

\begin{tabular}{lllll}
\hline & Cases & \begin{tabular}{l}
30 -day mortality \\
\cline { 2 - 4 }
\end{tabular} & & $\begin{array}{l}\text { Hospital } \\
\text { mortality }\end{array}$ \\
\hline $\begin{array}{l}\text { Heart transplantation } \\
\begin{array}{l}\text { Heart and lung } \\
\text { transplantation }\end{array}\end{array}$ & 44 & 0 & 0 & 0 \\
discharge & \\
Total & 44 & 0 & 0 & 0 \\
\hline
\end{tabular}

( ), \% mortality

Table 9 Pacemaker + ICD (total 4078)

\begin{tabular}{lrrrrrr}
\hline & \multicolumn{2}{l}{ Pacemaker } & & \multicolumn{2}{l}{ ICD } \\
\cline { 2 - 3 } \cline { 6 - 7 } & $\mathrm{V}$ & $\mathrm{A}-\mathrm{V}$ & $\mathrm{CRT}$ & & CRTD & ICD \\
\hline Initial & 442 & 1700 & 66 & & 158 & 251 \\
Exchange & 350 & 862 & 45 & & 93 & 111 \\
Unclear & 0 & 0 & 0 & 0 & 0 \\
Total & 792 & 2562 & 111 & & 251 & 362 \\
\hline
\end{tabular}

aneurysm were carried out in 9226 cases (decreased by $5.6 \%$ ), with overall hospital mortality of $6.0 \%$. The hospital mortality associated with unruptured aneurysm was $4.5 \%$, and that of ruptured aneurysm was $24.2 \%$, which remains markedly high.

The number of stent graft procedures remarkably increased recently. A total of 2521 patients with aortic dissection underwent stent graft placement: thoracic endovascular aortic repair (TEVAR) in 1650 cases and open stent grafting in 871 cases. The number of TEVAR for type B chronic aortic dissections increased from 835 cases in 2014 to 1065 cases in 2015 . The hospital mortality rates associated with TEVAR for type B aortic dissection were $8.9 \%$ in acute cases and $2.6 \%$ for chronic cases, respectively.

A total of 3935 patients with non-dissected aortic aneurysm underwent stent graft placement: TEVAR in 2912 cases (17.3\% decrease compared with that in 2014) and open stent grafting in 937 cases $(155 \%$ increase compared with that in 2014). The reason of striking increase of open stent grafting might be due to commercial availability since 2014. The hospital mortality rates for TEVAR and open stenting were as follows: TEVAR (3.2\% for unruptured, $21.7 \%$ for ruptured aneurysm,) and open stenting (7.2\% for unruptured and $25.6 \%$ for ruptured.)

In summary, the total cardiovascular operations decreased during 2015 by 2933 cases with steadily constant
General Thoracic Surgery

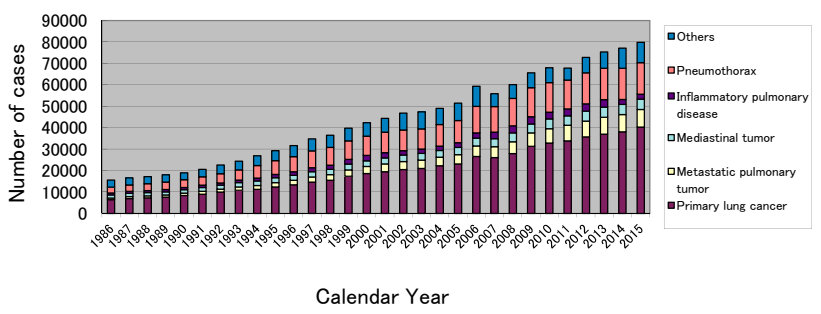

Fig. 2 General thoracic surgery

results in almost all categories. The main reason why the number of operations decreased in 2015 was the number of extra-anatomical bypass operations in thoracic aortic aneurysm and the number of trans-venous pacemaker implantations was excluded from the total number of cardiovascular operations in association with the change of data aggregation as was referred to earlier.

\section{(B) General thoracic surgery}

The 2015 survey of general thoracic surgery comprised 736 surgical units, and most data were submitted using the webbased collection system of the national clinical database

Table 10 Total entry cases of General Thoracic Surgery during 2015

\begin{tabular}{lrr}
\hline & Cases & \multicolumn{1}{c}{$\%$} \\
\hline Benign pulmonary tumor & 2161 & 2.7 \\
Primary lung cancer & 40,302 & 50.5 \\
Other primary malignant pulmonary tumor & 385 & 0.5 \\
Metastatic pulmonary tumor & 8226 & 10.3 \\
Tracheal tumor & 166 & 0.2 \\
Mesothelioma & 635 & 0.8 \\
Chest wall tumor & 677 & 0.8 \\
Mediastinal tumor & 4813 & 6.0 \\
Thymectomy for MG without thymoma & 164 & 0.2 \\
Inflammatory pulmonary disease & 2265 & 2.8 \\
Empyema & 2739 & 3.4 \\
Bullous disease excluding pneumothorax & 416 & 0.5 \\
Pneumothorax & 14,728 & 18.5 \\
Chest wall deformity & 174 & 0.2 \\
Diaphragmatic hernia including traumatic & 36 & 0.0 \\
Chest trauma excluding diaphragmatic hernia & 388 & 0.5 \\
Lung transplantation & 63 & 0.1 \\
Others & 1437 & 1.8 \\
Total & 79,775 & 100.0 \\
\hline & &
\end{tabular}


Table 11

1. Benign pulmonary tumor

\begin{tabular}{|c|c|c|c|c|c|c|}
\hline & \multirow[t]{2}{*}{ Cases } & \multicolumn{2}{|c|}{ 30-day mortality } & \multirow[t]{2}{*}{ Hospital mortality } & \multicolumn{2}{|c|}{ By VATS } \\
\hline & & Hospital & After discharge & & 2015 & $2014 *$ \\
\hline Hamartoma & 478 & 0 & 0 & 0 & 469 & 454 \\
\hline Sclerosing hemangioma & 125 & 0 & 0 & 0 & 118 & 96 \\
\hline Papilloma & 20 & 0 & 0 & 0 & 19 & 16 \\
\hline Mucous gland adenoma bronchial & 5 & 0 & 0 & 0 & 5 & 7 \\
\hline Fibroma & 166 & 0 & 0 & 0 & 162 & 128 \\
\hline Lipoma & 10 & 0 & 0 & 0 & 8 & 6 \\
\hline Neurogenic tumor & 15 & 0 & 0 & 0 & 13 & 16 \\
\hline Clear cell tumor & 4 & 0 & 0 & 0 & 4 & 2 \\
\hline Leiomyoma & 10 & 0 & 0 & 0 & 10 & 16 \\
\hline Chondroma & 6 & 0 & 0 & 0 & 6 & 4 \\
\hline Inflammatory myofibroblastic tumor & 3 & 0 & 0 & 0 & 3 & 1 \\
\hline Pseudolymphoma & 23 & 0 & 0 & 0 & 22 & 31 \\
\hline Histiocytosis & 20 & 0 & 0 & 0 & 19 & 22 \\
\hline Teratoma & 8 & 0 & 0 & 0 & 5 & 0 \\
\hline Others & 1268 & $1(0.1)$ & 0 & $3(0.2)$ & 1200 & 1266 \\
\hline Total & 2161 & $1(0.0)$ & 0 & $3(0.1)$ & 2063 & 2065 \\
\hline
\end{tabular}

( ) Mortality $\%$

*Unpublished reference data

(NCD) [1]. In total, 79,775 operations were reported by general thoracic surgery departments in 2015-1.8 times the number of operations in 2001 and 2705 more operations than in 2014 (Fig. 2).

In 2015, 40,302 operations for primary lung cancer were performed (Table 10), and the number has increased every year. The 2015 value is 2.1 times that of 2001 . Operations for lung cancer were $50.5 \%$ of all procedures in general thoracic surgery.

The number of video-assisted thoracic surgery (VATS) procedures in the NCD unexpectedly increased in 2014; however, the exact number of such procedures was not published. The increase was attributed to the use of a nonstandard definition of VATS for the NCD registry until 2013. The NCD registry previously included VATS procedures utilizing a skin incision longer than $8 \mathrm{~cm}$ and/or a minithoracotomy (hybrid) approach, which are traditionally not regarded as VATS procedures. In this report, the traditional VATS definition is used to describe the number of VATS procedures in the NCD. The number of VATS operations for benign pulmonary tumor, primary lung cancer, and the total number of VATS operation in 2014 and 2015 are shown in Tables 11, 12, 14, 17, 18, 19, 20, $21,22,23,24,26,27,28$, and 30 , respectively.

There were 2161 operations for benign pulmonary tumors in 2015, which was similar to the number in 2014
(Table 11). Hamartoma was the most frequent diagnosis in operations for benign pulmonary tumors. VATS was performed in 2063 patients (95.5\%). Additional information on primary malignant pulmonary tumors is shown in Tables 12 and 13. With regard to lung cancer subtype, adenocarcinoma was by far the most frequent diagnosis (70.0\% of all lung cancer operations), followed by squamous cell carcinoma (19.0\%). Sublobar resection was performed in 10,040 lung cancer cases ( $24.9 \%$ of all cases) and lobectomy was performed in 29,323 cases $(72.8 \%$ of all cases). Sleeve lobectomy was performed in 541 cases, and pneumonectomy was required in 533 cases $(1.3 \%$ of all cases). VATS lobectomy for lung cancer was performed in 18,078 cases $(61.7 \%)$. The number of VATS procedures for primary lung cancer was slightly higher than in 2014 .

In total, 129 patients died before hospital discharge within 30 days after lung cancer surgery, and 45 patients died after discharge within 30 days after lung cancer surgery. Therefore, 174 patients died within 30 days after lung cancer surgery (30-day mortality rate, $0.43 \%$ ). In total, 277 patients died before discharge (hospital mortality rate, $0.69 \%$ ), and the 30 -day mortality rate, by procedure, was $0.26 \%$ for segmentectomy, $0.44 \%$ for lobectomy, and $2.44 \%$ for pneumonectomy. Interstitial pneumonia was the leading cause of death after lung cancer surgery, followed 
Table 12

2. Primary malignant pulmonary tumor

\begin{tabular}{|c|c|c|c|c|c|c|}
\hline & \multirow[t]{2}{*}{ Cases } & \multirow[t]{2}{*}{ Hospital } & \multirow[t]{2}{*}{ After discharge } & \multirow[t]{2}{*}{ Hospital mortality } & \multicolumn{2}{|c|}{ By VATS } \\
\hline & & & & & 2015 & $2014 *$ \\
\hline \multicolumn{7}{|l|}{ 2. Primary malignant pulmonary tumor } \\
\hline Lung cancer & 40,687 & $129(0.3)$ & $45(0.1)$ & $275(0.7)$ & 26,188 & 24,306 \\
\hline Adenocarcinoma & 28,206 & $47(0.2)$ & $21(0.1)$ & $87(0.3)$ & & \\
\hline Squamous cell carcinoma & 7651 & $60(0.8)$ & $15(0.2)$ & $132(1.7)$ & & \\
\hline Large cell carcinoma & 744 & $5(0.7)$ & $1(0.1)$ & $14(1.9)$ & & \\
\hline$(L C N E C)$ & 465 & $2(0.4)$ & 0 & $10(2.2)$ & & \\
\hline Small cell carcinoma & 707 & $6(0.8)$ & 0 & $11(1.6)$ & & \\
\hline Adenosquamous carcinoma & 583 & $3(0.5)$ & $1(0.2)$ & $6(1.0)$ & & \\
\hline $\begin{array}{l}\text { Carcinoma with pleomorphic, sarcomatoid } \\
\text { or sarcomatous elements }\end{array}$ & 473 & $3(0.6)$ & $5(1.1)$ & $7(1.5)$ & & \\
\hline Carcinoid & 237 & $1(0.4)$ & 0 & $1(0.4)$ & & \\
\hline Carcinomas of salivary gland type & 35 & 0 & 0 & 0 & & \\
\hline Unclassified & 54 & $1(1.9)$ & 0 & $2(3.7)$ & & \\
\hline Multiple lung cancer & 1245 & $3(0.2)$ & 0 & $11(0.9)$ & & \\
\hline Others & 367 & 0 & $2(0.5)$ & $2(0.5)$ & & \\
\hline Wedge resection & 5810 & $10(0.2)$ & $4(0.1)$ & $25(0.4)$ & 4917 & 4359 \\
\hline Segmental excision & 4230 & $10(0.24)$ & $1(0.0)$ & $17(0.4)$ & 2950 & 2836 \\
\hline (Sleeve segmental excision) & 11 & 0 & 0 & 0 & 7 & 7 \\
\hline Lobectomy & 29,323 & $96(0.3)$ & $33(0.1)$ & $206(0.7)$ & 18,078 & 16,676 \\
\hline (Sleeve lobectomy) & 541 & $4(0.7)$ & $2(0.4)$ & $12(2.2)$ & 75 & 69 \\
\hline Pneumonectomy & 533 & $7(1.3)$ & $6(1.1)$ & $13(2.4)$ & 55 & 48 \\
\hline (Sleeve pneumonectomy) & 10 & 0 & 0 & $1(10.0)$ & 0 & 0 \\
\hline Other bronchoplasty & 43 & $2(4.7)$ & $1(2.3)$ & $4(9.3)$ & 5 & 5 \\
\hline Pleuropneumonectomy & 3 & 0 & 0 & 0 & 0 & 0 \\
\hline Others & 351 & $4(1.1)$ & 0 & $8(2.3)$ & 183 & 202 \\
\hline Unknown & 9 & 0 & 0 & 0 & & \\
\hline Sarcoma & 47 & 0 & 0 & $2(4.3)$ & & \\
\hline AAH & 109 & 0 & 0 & 0 & & \\
\hline Others & 229 & 0 & 0 & 0 & & \\
\hline
\end{tabular}

( ) Mortality \%

*Unpublished reference data

by pneumonia, respiratory failure, and cardiovascular events, as was the case in 2014.

Operations for metastatic pulmonary tumors are shown in Table 14; 8226 such operations were performed in 2015, an increase from the previous year. Colorectal cancer was the most frequent diagnosis (47.2\% of all cases).

There were 127 operations for malignant tracheal tumor in 2015 , but only 16 patients were treated with curative intent (Table 15).

There were 635 pleural tumors in 2015 (Table 16). Diffuse malignant pleural mesothelioma was the most frequent histologic diagnosis. Total pleurectomy was performed in 89 cases and extrapleural pneumonectomy in 80 cases. The hospital mortality rate was $4.5 \%$ after total pleurectomy and $5.0 \%$ after extrapleural pneumonectomy.

In total, 677 chest wall tumors were resected in 2015 (Table 17); $352(52.0 \%)$ were benign. Among the 325 malignant chest wall tumors, $195(60.0 \%)$ were metastatic tumors.

Mediastinal tumors were resected in 4813 patients, a slight increase from the previous year (Table 18). Thymic epithelial tumor-including 1912 thymomas, 336 thymic carcinomas, and 30 thymic neuroendocrine carcinomaswas the most frequent mediastinal tumor type in 2015 .

Thymectomy for myasthenia gravis was performed in 474 cases (Table 19); 310 cases were associated with 
Table 13 Details of lung cancer operation

\begin{tabular}{|c|c|}
\hline & Cases \\
\hline \multicolumn{2}{|l|}{ c-Stage (TNM) } \\
\hline Ia & 24,563 \\
\hline $\mathrm{Ib}$ & 7631 \\
\hline IIa & 3012 \\
\hline IIb & 1777 \\
\hline IIIa & 2504 \\
\hline IIIb & 160 \\
\hline IV & 480 \\
\hline NA & 175 \\
\hline Total & 40,302 \\
\hline \multicolumn{2}{|l|}{ Sex } \\
\hline Male & 24,882 \\
\hline Female & 15,420 \\
\hline NA & 0 \\
\hline Total & 40,302 \\
\hline \multicolumn{2}{|l|}{ Cause of death } \\
\hline Cardiovascular & 21 \\
\hline Pneumonia & 40 \\
\hline Pyothorax & 5 \\
\hline Bronchopleural fistula & 17 \\
\hline Respiratory failure & 31 \\
\hline Pulmonary embolism & 5 \\
\hline Interstitial pneumonia & 99 \\
\hline Brain infarction or bleeding & 19 \\
\hline Others & 75 \\
\hline Unknown & 6 \\
\hline Total & 318 \\
\hline \multicolumn{2}{|l|}{ p-Stage } \\
\hline $0(\mathrm{pCR})$ & 418 \\
\hline Ia & 21,131 \\
\hline $\mathrm{Ib}$ & 7928 \\
\hline IIa & 3280 \\
\hline IIb & 2088 \\
\hline IIIa & 4020 \\
\hline IIIb & 194 \\
\hline IV & 1027 \\
\hline NA & 216 \\
\hline Total & 40,302 \\
\hline \multicolumn{2}{|l|}{ Age } \\
\hline$<20$ & 49 \\
\hline $20-29$ & 32 \\
\hline $30-39$ & 234 \\
\hline $40-49$ & 1066 \\
\hline $50-59$ & 3716 \\
\hline 60-69 & 13,276 \\
\hline $70-79$ & 16,954 \\
\hline $80-89$ & 4912 \\
\hline$\geq 90$ & 62 \\
\hline NA & 1 \\
\hline Total & 40,302 \\
\hline
\end{tabular}

thymoma and the remaining cases were not associated with thymoma.

There were 2265 cases of lung resection for inflammatory lung diseases (Table 20); 34.2\% of the cases were inflammatory tumors of unknown origin, $22.2 \%$ were atypical mycobacterium infections, and $13.6 \%$ were fungal infections.

The 2739 operations for empyema (Table 21) comprised 1999 cases $(73.0 \%)$ of acute empyema and 740 cases of chronic empyema. Bronchopleural fistula was reported in 466 patients $(23.3 \%)$ with acute empyema and 325 patients (43.9\%) with chronic empyema. The hospital mortality rate was $16.5 \%$ in patients with acute empyema with fistula.

There were 98 operations for descending necrotizing mediastinitis (Table 22). The hospital mortality rate was $8.2 \%$

There were 416 operations for bullous diseases (Table 23). Lung volume reduction surgery was performed in only 21 patients.

The NCD showed 14,728 operations for spontaneous pneumothorax (Table 24). The 11,816 operations for primary pneumothorax comprised 3118 patients $(26.4 \%)$ who underwent bullectomy only and 7805 patients $(66.1 \%)$ who underwent an additional procedure. There were 2851 operations for secondary pneumothorax. COPD was by far the most prevalent associated disease (69.5\%). The hospital mortality rate for secondary pneumothorax associated with COPD was $3.1 \%$.

The 2015 survey reported 174 operations for chest wall deformity (Table 25). However, this might be an underestimate, because the Nuss procedure was more likely to have been performed in centers not associated with JATS.

Diaphragmatic hernia was treated surgically in 36 patients (Table 26). This figure might be an underestimate, as some procedures might have been classified as gastrointestinal surgery.

The survey reported 388 procedures for chest trauma excluding iatrogenic injuries (Table 27). The hospital mortality rate was $6.7 \%$.

Table 28 shows operations for other diseases, including 82 cases of arteriovenous malformation and 90 cases of pulmonary sequestration.

A total of 63 lung transplantations were performed in 2015 (Table 29): 47 patients received lung transplants from brain-dead donors and 16 received transplants from livingrelated donors. The number of lung transplantation procedures has remained constant for several years.

The number of VATS procedures has increased annually, reaching 60,735 in 2015 (Table 30).

The details of tracheobronchoplasty, pediatric surgery, and combined resection of neighboring organs are shown in Tables 31, 32, 33 and 34. 
Table 14

3. Metastatic pulmonary tumor

\begin{tabular}{lllllll}
\hline & Cases & \multicolumn{2}{l}{30 -day mortality } & \multirow{2}{*}{ Hospital mortality } & \multicolumn{2}{l}{ By VATS } \\
\cline { 3 - 4 } \cline { 7 - 8 } & & Hospital & After discharge & & 2015 & $2014 *$ \\
\hline 3. Metastatic pulmonary tumor & 8226 & $13(0.2)$ & $5(0.1)$ & $25(0.3)$ & 7593 & 7424 \\
Colorectal & 3886 & $2(0.1)$ & $3(0.1)$ & $6(0.2)$ & 3589 & 3618 \\
Hepatobiliary/pancreatic & 352 & 0 & $1(0.3)$ & $1(0.3)$ & 327 & 332 \\
Uterine & 475 & 0 & 0 & 0 & 446 & 363 \\
Mammary & 474 & $1(0.2)$ & 0 & $1(0.2)$ & 448 & 420 \\
Ovarian & 74 & 0 & 0 & 0 & 71 & 56 \\
Testicular & 65 & 0 & 0 & $1(1.5)$ & 58 & 77 \\
Renal & 653 & 0 & 0 & 0 & 627 & 589 \\
Skeletal & 118 & 0 & 0 & 0 & 107 & 135 \\
Soft tissue & 249 & $1(0.4)$ & 0 & $2(0.8)$ & 219 & 212 \\
Otorhinolaryngological & 460 & 0 & 0 & $2(0.4)$ & 425 & 385 \\
Pulmonary & 480 & $3(0.6)$ & 0 & $5(1.0)$ & 394 & 407 \\
Others & 940 & $6(0.6)$ & $1(0.1)$ & $7(0.7)$ & 882 & 830 \\
\hline
\end{tabular}

( ) Mortality $\%$

*Unpublished reference data
Table 15

4. Tracheal tumor

\begin{tabular}{|c|c|c|c|c|}
\hline & \multirow[t]{2}{*}{ Cases } & \multicolumn{2}{|c|}{ 30-day mortality } & \multirow[t]{2}{*}{ Hospital mortality } \\
\hline & & Hospital & After discharge & \\
\hline 4. Tracheal tumor & 166 & $4(2.4)$ & $3(1.8)$ & $6(3.6)$ \\
\hline \multicolumn{5}{|l|}{ A. Primary malignant tumor } \\
\hline \multicolumn{5}{|l|}{ Histological classification } \\
\hline Squamous cell carcinoma & 17 & $1(5.9)$ & $1(5.9)$ & $1(5.9)$ \\
\hline Adenoid cystic carcinoma & 21 & 0 & 0 & 0 \\
\hline Mucoepidermoid carcinoma & 4 & 0 & 0 & 0 \\
\hline Others & 17 & 0 & 0 & 0 \\
\hline Total & 59 & $1(1.7)$ & $1(1.7)$ & $1(1.7)$ \\
\hline \multicolumn{5}{|l|}{ B. Metastatic/invasive malignant tumor } \\
\hline E.g., invasion of thyroid cancer & 68 & $3(4.4)$ & $2(2.9)$ & $5(7.4)$ \\
\hline \multicolumn{5}{|l|}{ C. Benign tracheal tumor } \\
\hline \multicolumn{5}{|l|}{ Histological classification } \\
\hline Papilloma & 1 & 0 & 0 & 0 \\
\hline Adenoma & 3 & 0 & 0 & 0 \\
\hline Neurofibroma & 0 & 0 & 0 & 0 \\
\hline Chondroma & 0 & 0 & 0 & 0 \\
\hline Leiomyoma & 4 & 0 & 0 & 0 \\
\hline Others & 31 & 0 & 0 & 0 \\
\hline Histology unknown & 0 & 0 & 0 & 0 \\
\hline Total & 39 & 0 & 0 & 0 \\
\hline \multicolumn{5}{|l|}{ Operation } \\
\hline Sleeve resection with reconstruction & 13 & 0 & 0 & $1(7.7)$ \\
\hline Wedge with simple closure & 2 & 0 & 0 & 0 \\
\hline Wedge with patch closure & 0 & & 0 & 0 \\
\hline Total laryngectomy with tracheostomy & 0 & 0 & 0 & 0 \\
\hline Others & 1 & 0 & 0 & 0 \\
\hline Unknown & 0 & 0 & 0 & 0 \\
\hline Total & 16 & 0 & 0 & $1(6.3)$ \\
\hline
\end{tabular}

( ) Mortality $\%$ 
Table 16

5. Tumor of pleural origin

\begin{tabular}{lrlll}
\hline 5. Tumor of pleural origin & Cases & \multicolumn{2}{l}{30 -day mortality } & Hospital mortality \\
& & Hospital & After discharge & \\
\hline Histological classification & & & & \\
$\quad$ Solitary fibrous tumor & 116 & 0 & 0 & 0 \\
Diffuse malignant pleural mesothelioma & 280 & $4(1.4)$ & $3(1.1)$ & $9(3.2)$ \\
Localized malignant pleural mesothelioma & 36 & 0 & 0 & 0 \\
Others & 203 & $1(0.5)$ & 0 & $3(1.5)$ \\
Total & 635 & $5(0.8)$ & $3(0.5)$ & $12(1.9)$ \\
Operative procedure & & & & $4(5.0)$ \\
Extrapleural pneumonectomy & 80 & $1(1.3)$ & 0 & $4(4.5)$ \\
Total pleurectomy & 89 & $2(2.2)$ & 0 & $1(0.9)$ \\
Others & 111 & $1(0.9)$ & $3(2.7)$ & $9(3.2)$ \\
Total & 280 & $4(1.4)$ & $3(1.1)$ & \\
\hline
\end{tabular}

( ) Mortality $\%$

\begin{tabular}{llllllr}
\hline 6. Chest wall tumor & Cases & \multicolumn{2}{l}{ 30-day mortality } & Hospital mortality & \multicolumn{2}{c}{ By VATS } \\
\cline { 3 - 4 } & & Hospital & After discharge & & 2015 & $2014^{*}$ \\
\hline Primary malignant tumor & 130 & 0 & 0 & 0 & 54 & 57 \\
Metastatic malignant tumor & 195 & 0 & $1(0.5)$ & $1(0.5)$ & 62 & 81 \\
Benign tumor & 352 & 0 & 0 & $1(0.3)$ & 264 & 274 \\
Total & 677 & 0 & $1(0.1)$ & $2(0.3)$ & 380 & 412 \\
\hline
\end{tabular}

( ) Mortality $\%$

*Unpublished reference data
Table 17

6. Chest wall tumor

Table 18

7. Mediastinal tumor

\begin{tabular}{|c|c|c|c|c|c|c|}
\hline & \multirow[t]{2}{*}{ Cases } & \multicolumn{2}{|c|}{ 30-day mortality } & \multirow[t]{2}{*}{ Hospital mortality } & \multicolumn{2}{|c|}{ By VATS } \\
\hline & & Hospital & After discharge & & 2015 & $2014 *$ \\
\hline 7. Mediastinal tumor & 4813 & $3(0.1)$ & $3(0.06)$ & $9(0.2)$ & 3369 & 3208 \\
\hline Thymoma* & 1912 & $2(0.1)$ & 0 & $3(0.2)$ & 1127 & 1016 \\
\hline Thymic cancer & 336 & 0 & 0 & $1(0.3)$ & 167 & 143 \\
\hline Thymus carcinoid & 30 & 0 & 0 & 0 & 20 & 15 \\
\hline Germ cell tumor & 107 & 0 & 0 & 0 & 58 & 56 \\
\hline Benign & 82 & 0 & 0 & 0 & 47 & 47 \\
\hline Malignant & 25 & 0 & 0 & 0 & 11 & 9 \\
\hline Neurogenic tumor & 424 & 0 & $1(0.2)$ & 0 & 397 & 440 \\
\hline Congenital cyst & 1026 & 0 & 0 & 0 & 924 & 811 \\
\hline Goiter & 84 & $1(1.2)$ & $1(1.2)$ & $1(1.2)$ & 24 & 19 \\
\hline Lymphatic tumor & 186 & 0 & 0 & $2(1.1)$ & 141 & 155 \\
\hline Excision of pleural recurrence of thymoma & 27 & 0 & 0 & 0 & 23 & 31 \\
\hline Thymolipoma & 15 & 0 & 0 & 0 & 10 & 9 \\
\hline Others & 666 & 0 & $1(0.2)$ & $2(0.3)$ & 478 & 513 \\
\hline
\end{tabular}

( ) Mortality \%

*Unpublished reference data 
Table 19

8. Thymectomy for myasthenia gravis

\begin{tabular}{|c|c|c|c|c|c|c|}
\hline & \multirow[t]{2}{*}{ Cases } & \multicolumn{2}{|c|}{ 30-day mortality } & \multirow[t]{2}{*}{ Hospital mortality } & \multicolumn{2}{|c|}{ By VATS } \\
\hline & & Hospital & After discharge & & 2015 & $2014 *$ \\
\hline 8. Thymectomy for myasthenia gravis & 474 & $3(0.6)$ & 0 & $4(0.8)$ & 248 & 269 \\
\hline With thymoma & 310 & $2(0.6)$ & 0 & $3(1.0)$ & 152 & 161 \\
\hline
\end{tabular}

( ) Mortality \%

*Unpublished reference data

Table 20

9. Operations for non-neoplastic disease(A) Inflammatory pulmonary disease

\begin{tabular}{|c|c|c|c|c|c|c|}
\hline \multirow[t]{2}{*}{ Cases } & \multicolumn{3}{|c|}{ 30-day mortality } & & \multicolumn{2}{|c|}{ Hospital mortality } \\
\hline & \multicolumn{2}{|l|}{ Hospital } & \multicolumn{2}{|l|}{ After discharge } & & \\
\hline \multirow[t]{3}{*}{22,183} & \multicolumn{2}{|l|}{$175(0.8)$} & \multirow[t]{2}{*}{$33(0.1)$} & & \multicolumn{2}{|c|}{$428(1.9)$} \\
\hline & \multirow[t]{2}{*}{ Cases } & 30-day mortality & & \multirow[t]{2}{*}{ Hospital mortality } & \multicolumn{2}{|c|}{ By VATS } \\
\hline & & Hospital & After discharge & & 2015 & $2014 *$ \\
\hline (A) Inflammatory pulmonary disease & 2265 & $8(0.4)$ & $3(0.1)$ & $24(1.1)$ & 2004 & 1958 \\
\hline Tuberculous infection & 68 & 0 & 0 & 0 & 57 & 60 \\
\hline Mycobacterial infection & 503 & 0 & 0 & 0 & 449 & 435 \\
\hline Fungal infection & 309 & $5(1.6)$ & 0 & $7(2.3)$ & 236 & 249 \\
\hline Bronchiectasis & 67 & 0 & 0 & $3(4.5)$ & 49 & 54 \\
\hline Tuberculous nodule & 106 & 0 & $1(0.9)$ & 0 & 103 & 120 \\
\hline Inflammatory pseudo tumor & 776 & 0 & $1(0.1)$ & $1(0.1)$ & 734 & 508 \\
\hline Interpulmonary lymph node & 56 & 0 & 0 & 0 & 56 & 59 \\
\hline Others & 380 & $3(0.8)$ & $1(0.3)$ & $13(3.4)$ & 320 & 473 \\
\hline
\end{tabular}

( ) Mortality \%

*Unpublished reference data

\section{(C) Esophageal surgery}

During 2015 alone, a total of 12,732 patients with esophageal diseases were registered from 571 institutions (response rate: 93.6\%) affiliated to the Japanese Association for Thoracic Surgery and/or to the Japan Esophageal Society. Among these institutions, those where 20 or more patients underwent esophageal surgeries within the year of 2015 were 136 institutions (23.8\%), which shows no definite shift of esophageal operations to high-volume institutions when compared to the data of 2014 (22.1\%) (Table 35). Of 2991 patients with a benign esophageal disease, 1619 (54.1\%) patients underwent surgery, and 77 (2.6\%) patients underwent endoscopic resection, while $1295(43.3 \%)$ patients did not undergo any surgical treatment (Table 36). Of 10,288 patients with a malignant esophageal tumor, $8106(78.8 \%)$ patients underwent resection, esophagectomy for 6151 (59.8\%) and endoscopic mucosal resection (EMR) or endoscopic submucosal dissection (ESD) for 1955 (19.0\%), while 2182 (21.2\%) patients did not undergo any resection (Tables 37,38 ). The patients registered, particularly those undergoing non-surgical therapy for a malignant esophageal disease, have been increasing since 1990 (Fig. 3).

Among benign esophageal diseases (Table 36), hiatal hernia, esophageal varices, esophagitis (including reflux esophagitis) and achalasia were the most common conditions in Japan. On the other hand, spontaneous rupture of the esophagus, benign esophageal tumors and congenital esophageal atresia were common diseases which were surgically treated as well as the above-mentioned diseases. The thoracoscopic and/or laparoscopic procedures have been widely adopted for benign esophageal diseases, in particular achalasia, hiatal hernia and benign tumors. Open 
Table 21

9. Operations for non-neoplastic disease

(B) Empyema

\begin{tabular}{|c|c|c|c|c|c|c|}
\hline & \multirow[t]{2}{*}{ Cases } & \multicolumn{2}{|c|}{ 30-day mortality } & \multirow[t]{2}{*}{ Hospital mortality } & \multicolumn{2}{|c|}{ By VATS } \\
\hline & & Hospital & After discharge & & 2015 & $2014 *$ \\
\hline Acute empyema & 1999 & $45(2.3)$ & $8(0.4)$ & $131(6.6)$ & 1657 & 1574 \\
\hline With fistula & 466 & $27(5.8)$ & $3(0.6)$ & $77(16.5)$ & 275 & 274 \\
\hline Without fistula & 1516 & $18(1.2)$ & $5(0.3)$ & $52(3.4)$ & 1369 & 1279 \\
\hline Unknown & 17 & 0 & 0 & $2(11.8)$ & 13 & 21 \\
\hline Chronic empyema & 740 & $10(1.4)$ & $2(0.3)$ & $53(7.2)$ & 404 & 368 \\
\hline With fistula & 325 & $5(1.5)$ & $1(0.3)$ & $33(10.2)$ & 126 & 132 \\
\hline Without fistula & 367 & $5(1.4)$ & $1(0.3)$ & $18(4.9)$ & 248 & 214 \\
\hline Unknown & 48 & 0 & 0 & $2(4.2)$ & 30 & 22 \\
\hline Total, \% & 2739 & $55(2.0)$ & $10(0.4)$ & $184(6.7)$ & 2061 & 1942 \\
\hline
\end{tabular}

( ) Mortality \%

*Unpublished reference data

\begin{tabular}{|c|c|c|c|c|c|}
\hline \multirow[t]{2}{*}{ Cases } & \multicolumn{2}{|c|}{ 30-day mortality } & \multirow[t]{2}{*}{ Hospital mortality } & \multicolumn{2}{|c|}{ By VATS } \\
\hline & Hospital & After discharge & & 2015 & $2014 *$ \\
\hline \multicolumn{6}{|c|}{ (C) Descending necrotizing mediastinitis } \\
\hline 98 & $2(2.0)$ & 0 & $8(8.2)$ & 70 & 80 \\
\hline
\end{tabular}

( ) Mortality $\%$

*Unpublished reference data

Table 23

9. Operations for non-neoplastic disease

(D) Bullous disease

\begin{tabular}{|c|c|c|c|c|c|c|}
\hline & \multirow[t]{2}{*}{ Cases } & \multicolumn{2}{|c|}{ 30-day mortality } & \multirow[t]{2}{*}{ Hospital mortality } & \multicolumn{2}{|c|}{ By VATS } \\
\hline & & Hospital & After discharge & & 2015 & $2014 *$ \\
\hline (D) Bullous disease & 416 & $1(0.2)$ & 0 & $2(0.5)$ & 393 & 366 \\
\hline Emphysematous bulla & 330 & $1(0.3)$ & 0 & $2(0.6)$ & 314 & 288 \\
\hline Bronchogenic cyst & 16 & 0 & 0 & 0 & 14 & 15 \\
\hline Emphysema with volume reduction surgery & 21 & 0 & 0 & 0 & 20 & 23 \\
\hline Others & 49 & 0 & 0 & 0 & 45 & 40 \\
\hline
\end{tabular}

LVRS lung volume reduction surgery

( ) Mortality \%

surgery was performed in $1072(66.2 \%)$ patients with a benign esophageal disease, with 30-day mortality in 7 $(0.7 \%)$, while thoracoscopic and/or laparoscopic surgery was performed for $547(33.8 \%)$ patients, with none of the 30-day mortality. The difference in these death rates between open and scopic surgery seems to be related to the conditions requiring open surgery.

The majority of malignant diseases were carcinomas (Table 37). Among esophageal carcinomas, the incidence of squamous cell carcinoma was $90.1 \%$, while that of adenocarcinomas including Barrett cancer was $7.2 \%$. The resection rate for patients with a squamous cell carcinoma was $77.9 \%$, while that for patients with an adenocarcinoma was $88.9 \%$.

According to location, cancer in the thoracic esophagus was the most common (Table 38). Of the 4137 patients (40.2\% of total esophageal malignancies) having superficial esophageal cancers within mucosal and submucosal 
Table 24

9. Operations for non-neoplastic disease

(E) Pneumothorax

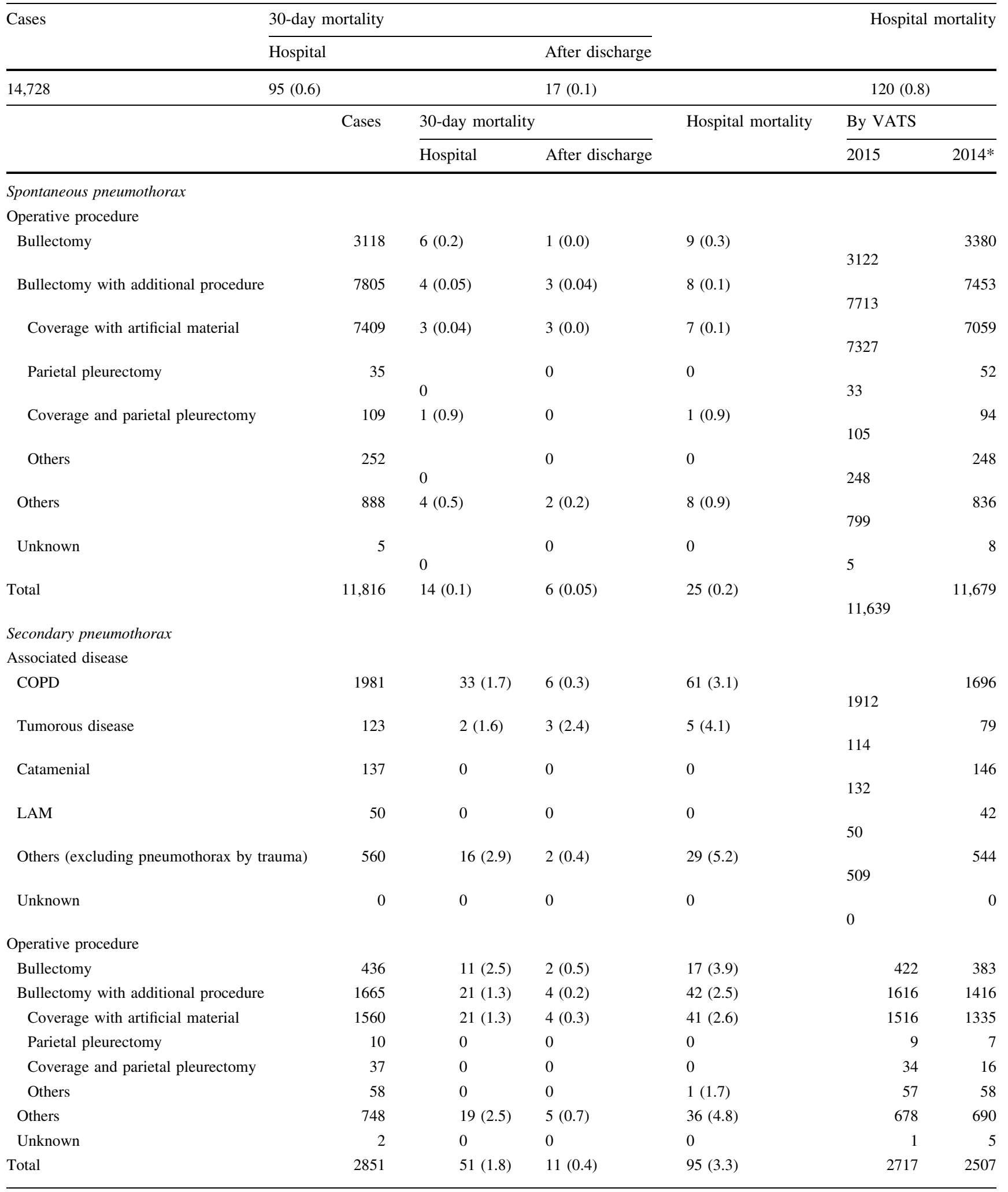

( ) Mortality $\%$

*Unpublished reference data 
Table 25

9. Operations for non-neoplastic disease

(F) Chest wall deformity

\begin{tabular}{lrlll}
\hline & Cases & \multicolumn{2}{l}{30 -day mortality } & $\begin{array}{l}\text { Hospital } \\
\text { mortality }\end{array}$ \\
\cline { 3 - 4 } & & \multicolumn{3}{l}{$\begin{array}{l}\text { Hospital } \\
\text { After } \\
\text { discharge }\end{array}$} \\
\hline (F) Chest wall deformity & 174 & 0 & 0 & 0 \\
Funnel chest & 167 & 0 & 0 & 0 \\
Others & 7 & 0 & 0 & 0 \\
\hline
\end{tabular}

( ) Mortality \% layers, $6151(59.8 \%)$ patients underwent esophagectomy, while 1955 (19.0\%) patients underwent EMR or ESD. The 30-day mortality rate and hospital mortality rate after esophagectomy for patients with a superficial cancer were 0.5 and $1.7 \%$ (141/6151), respectively.

Multiple primary cancers were observed in 1816 (17.7\%) of all the 10,288 patients with esophageal cancer. Synchronous cancer was found in 960 (9.3\%) patients, while metachronous cancer was observed in $856(8.3 \%)$ patients. The stomach is the commonest site for both

Table 26

9. Operations for non-neoplastic disease

(G) Diaphragmatic hernia

\begin{tabular}{|c|c|c|c|c|c|c|}
\hline & \multirow[t]{2}{*}{ Cases } & \multicolumn{2}{|c|}{ 30-day mortality } & \multirow[t]{2}{*}{ Hospital mortality } & \multicolumn{2}{|c|}{ By VATS } \\
\hline & & Hospital & After discharge & & 2015 & $2014 *$ \\
\hline (G) Diaphragmatic hernia & 36 & 0 & 0 & 0 & 22 & 24 \\
\hline Congenital & 3 & 0 & 0 & 0 & 3 & 8 \\
\hline Traumatic & 12 & 0 & 0 & 0 & 7 & 3 \\
\hline Others & 21 & 0 & 0 & 0 & 12 & 13 \\
\hline
\end{tabular}

( ) Mortality \%

*Unpublished reference data

Table 27

9. Operations for non-neoplastic disease

(H) Chest trauma

\begin{tabular}{|c|c|c|c|c|c|c|}
\hline & \multirow[t]{2}{*}{ Cases } & \multicolumn{2}{|c|}{ 30-day mortality } & \multirow[t]{2}{*}{ Hospital mortality } & \multicolumn{2}{|c|}{ By VATS } \\
\hline & & Hospital & After discharge & & 2015 & $2014 *$ \\
\hline (H) Chest trauma & 388 & $17(4.4)$ & 0 & $26(6.7)$ & 243 & 239 \\
\hline
\end{tabular}

( ) Mortality \%

*Unpublished reference data

Table 28

9. Operations for non-neoplastic disease

(I) Other respiratory surgery

\begin{tabular}{|c|c|c|c|c|c|c|}
\hline & \multirow[t]{2}{*}{ Cases } & \multicolumn{2}{|c|}{ 30-day mortality } & \multirow[t]{2}{*}{ Hospital mortality } & \multicolumn{2}{|c|}{ By VATS } \\
\hline & & Hospital & After discharge & & 2015 & $2014 *$ \\
\hline (I) Other respiratory surgery & 1339 & $27(2.0)$ & $3(0.2)$ & $64(4.8)$ & 953 & 957 \\
\hline Arteriovenous malformation* & 82 & 0 & 0 & 0 & 77 & 70 \\
\hline Pulmonary sequestration & 90 & 0 & 0 & 0 & 73 & 89 \\
\hline Postoperative bleeding $>$ air leakage & 385 & $11(2.9)$ & 0 & $27(7.0)$ & 273 & 255 \\
\hline Chylothorax & 64 & $2(3.1)$ & 0 & $2(3.1)$ & 55 & 52 \\
\hline Others & 718 & $14(1.9)$ & $3(0.4)$ & $35(4.9)$ & 475 & 491 \\
\hline
\end{tabular}

( ) Mortality \%

*Unpublished reference data 
Table 29

10. Lung transplantation

\begin{tabular}{lllll}
\hline & Cases & \multicolumn{2}{l}{ 30-day mortality } & Hospital mortality \\
\cline { 4 - 5 } & & Hospital & After discharge & $2(8.7)$ \\
\hline Single lung transplantation from brain-dead donor & 23 & $1(4.3)$ & 0 & $1(4.2)$ \\
Bilateral lung transplantation from brain-dead donor & 24 & 0 & 0 & $1(6.3)$ \\
Lung transplantation from living donor & 16 & $1(1.6)$ & 0 & $4(6.3)$ \\
Total of lung transplantation & 63 & 0 & 0 & 0 \\
Donor of living donor lung transplantation & 31 & 0 & 0 \\
\hline
\end{tabular}

( ) Mortality \%

Table 30

11. Video-assisted thoracic surgery

\begin{tabular}{|c|c|c|c|c|c|}
\hline & & \multirow[t]{2}{*}{ Cases } & \multicolumn{2}{|c|}{ 30-day mortality } & \multirow[t]{2}{*}{ Hospital mortality } \\
\hline & & & Hospital & After discharge & \\
\hline \multirow[t]{2}{*}{ 11. Video-assisted thoracic surgery } & 2015 & 60,735 & $186(0.3)$ & $59(0.10)$ & $396(0.7)$ \\
\hline & $2014 *$ & 58,259 & $194(0.3)$ & $43(0.07)$ & $437(0.8)$ \\
\hline
\end{tabular}

*Unpublished reference data

( ) Mortality \% (including thoracic sympathectomy 160)

Table 31

12. Tracheobronchoplasty

\begin{tabular}{lclll}
\hline & Cases & \multicolumn{2}{l}{30 -day mortality } & Hospital mortality \\
\cline { 4 - 5 } & & Hospital & After discharge \\
\hline 12. Tracheobronchoplasty & 703 & $9(1.3)$ & $2(6.9)$ & $21(3.0)$ \\
Trachea & 29 & 0 & 0 & $2(6.9)$ \\
Sleeve resection with reconstruction & 16 & 0 & 0 & 0 \\
Wedge with simple closure & 5 & 0 & 0 & 0 \\
Wedge with patch closure & 0 & 0 & 0 & 0 \\
Total laryngectomy with tracheostomy & 0 & $2(25.0)$ & 0 & $2(25.0)$ \\
Others & 8 & 0 & $1(3.0)$ & 0 \\
Carinal reconstruction & 33 & 0 & 0 & $1(9.1)$ \\
Sleeve pneumonectomy & 11 & $5(0.9)$ & $2(0.4)$ & $13(2.4)$ \\
Sleeve lobectomy & 536 & 0 & 0 & 0 \\
Sleeve segmental excision & 17 & 0 & 0 & 0 \\
Bronchoplasty without lung resection & 14 & $2(3.2)$ & $2(3.2)$ & $5(7.9)$ \\
Others & 63 & &
\end{tabular}

( ) Mortality \%

Table 32

13. Pediatric surgery

\begin{tabular}{|c|c|c|c|c|}
\hline & \multirow[t]{2}{*}{ Cases } & \multicolumn{2}{|c|}{ 30-day mortality } & \multirow{2}{*}{$\begin{array}{l}\text { Hospital } \\
\text { mortality }\end{array}$} \\
\hline & & Hospital & $\begin{array}{l}\text { After } \\
\text { discharge }\end{array}$ & \\
\hline $\begin{array}{l}\text { 13. Pediatric } \\
\text { surgery }\end{array}$ & 359 & $4(1.1)$ & 0 & $6(1.7)$ \\
\hline
\end{tabular}

( ) Mortality \% synchronous and metachronous malignancy followed by head and neck cancer (Table 38).

Among esophagectomy procedures, transthoracic esophagectomy through right thoracotomy was the most commonly adopted for patients with a superficial cancer as well as for those with an advanced cancer (Table 39). Transhiatal esophagectomy commonly performed in Western countries was adopted in only $2.8 \%$ of patients having 
Table 33

14. Combined resection of neighboring organ(s)

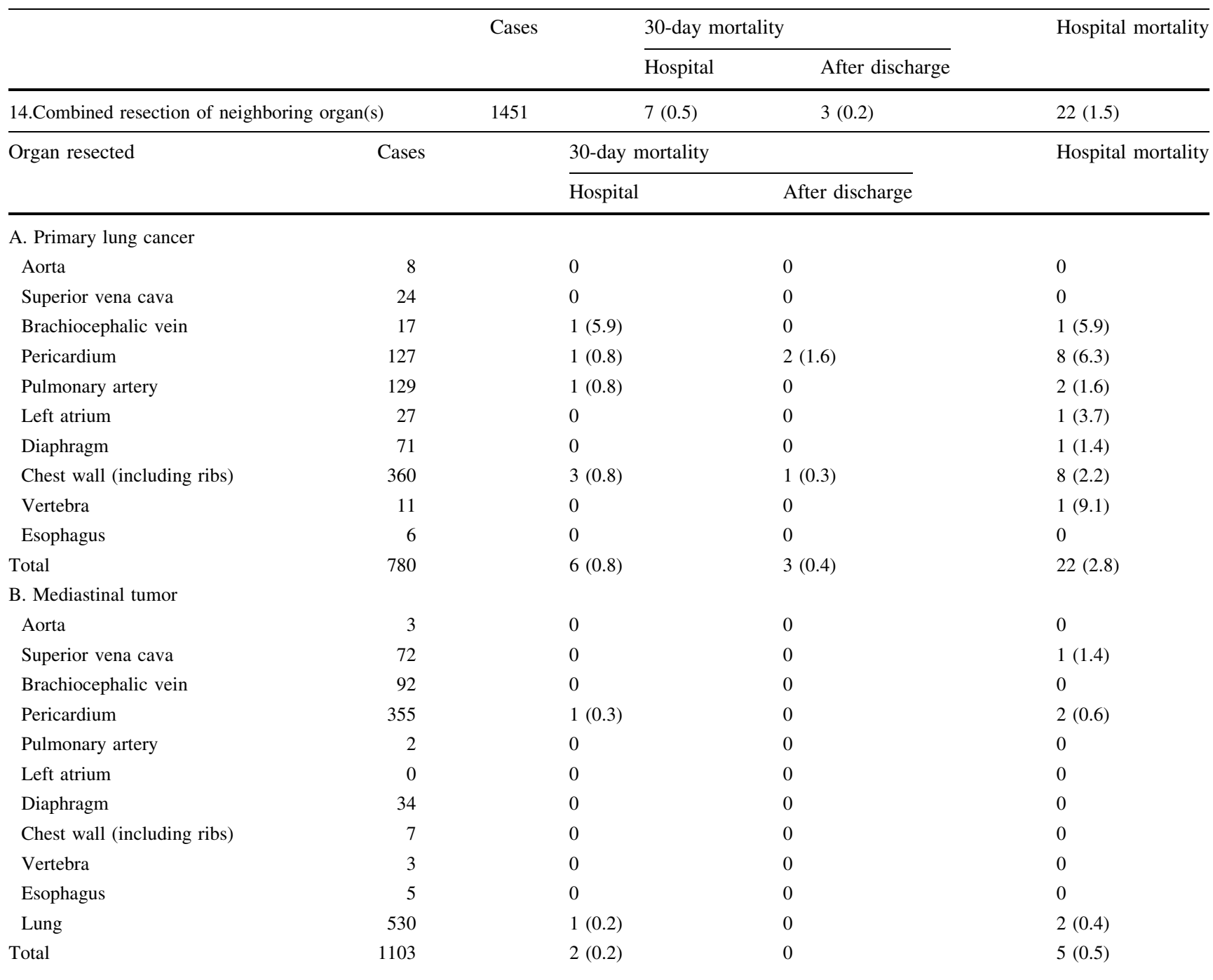

( ) Mortality \%

Table 34

15. Operation of lung cancer invading the chest wall of the apex

\begin{tabular}{lllll}
\hline & Cases & \begin{tabular}{l}
30 -day mortality \\
\cline { 3 - 4 }
\end{tabular} & & $\begin{array}{l}\text { Hospital } \\
\text { mortality }\end{array}$ \\
\hline $\begin{array}{l}\text { Hospital } \\
\begin{array}{l}\text { 15.Operation of lung } \\
\text { cancer invading the } \\
\text { discharge }\end{array}\end{array}$ & 741 & $2(0.3)$ & $4(0.5)$ & $7(0.9)$ \\
\hline
\end{tabular}

( ) Mortality $\%$

Includes tumors invading the anterior apical chest wall and posterior apical chest wall (superior sulcus tumor, so-called Pancoast type)

a superficial cancer who underwent esophagectomy and in $1.4 \%$ of those having an advanced cancer in Japan. The thoracoscopic and/or laparoscopic esophagectomy were adopted for 1036 patients (51.3\%) with a superficial
Table 35 Distribution of number of esophageal operations in 2015 in each institution

\begin{tabular}{lclc}
\hline \multicolumn{3}{l}{ Esophageal surgery } & \\
\hline $\begin{array}{l}\text { Number of } \\
\text { operations in } \\
2015\end{array}$ & $\begin{array}{l}\text { Benign } \\
\text { esophageal } \\
\text { diseases }\end{array}$ & $\begin{array}{l}\text { Malignant } \\
\text { esophageal } \\
\text { disease }\end{array}$ & Benign + malignant \\
\hline 0 & 267 & 117 & 81 \\
$1-4$ & 241 & 145 & 151 \\
$5-9$ & 43 & 108 & 101 \\
$10-19$ & 14 & 80 & 102 \\
$20-29$ & 3 & 42 & 46 \\
$30-39$ & 1 & 26 & 29 \\
$40-49$ & 1 & 12 & 13 \\
$\geqq 50$ & 1 & 41 & 48 \\
Total & 571 & 571 & 571 \\
\hline
\end{tabular}




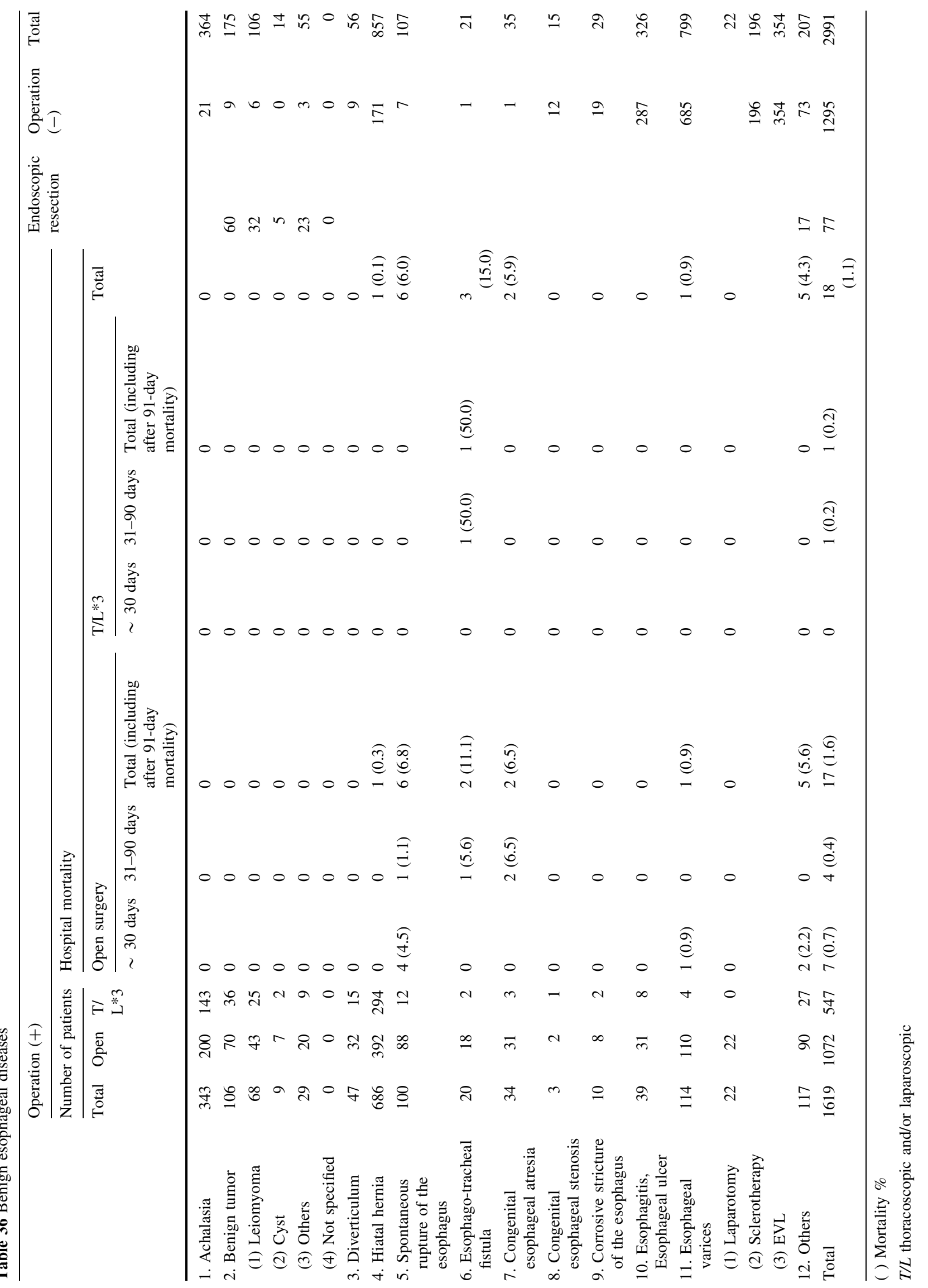




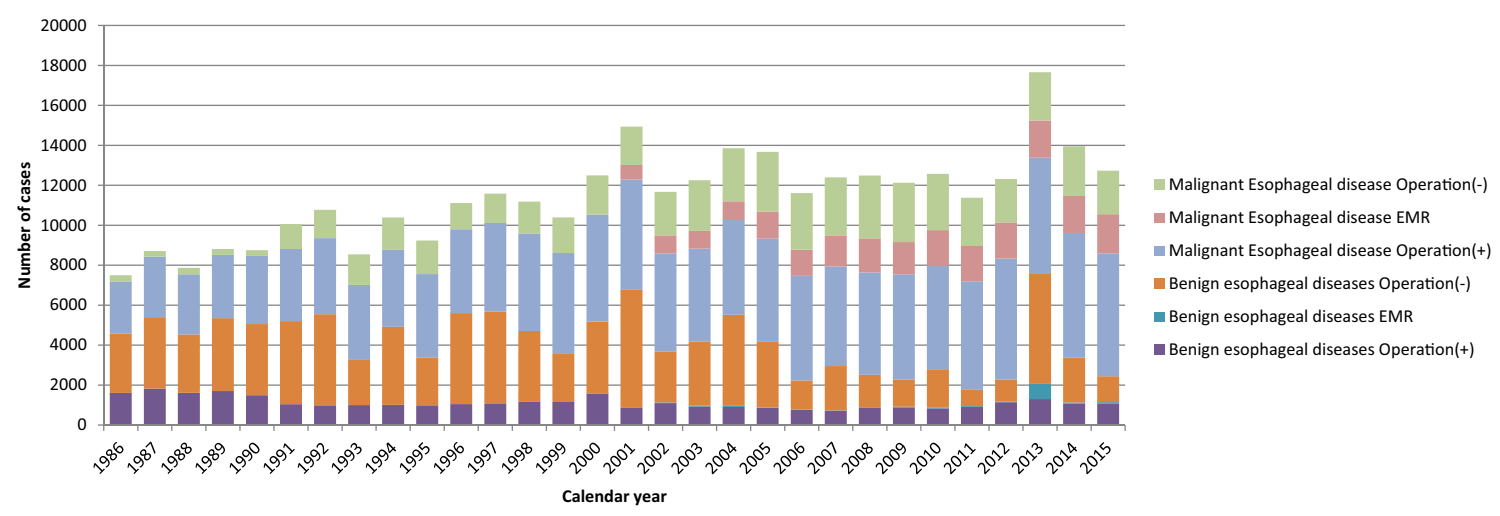

Fig. 3 Annual trend of in-patients with esophageal diseases. EMR endoscopic mucosal resection (including endoscopic submucosal)

Table 37 Malignant esophageal diseases (histologic classification)

\begin{tabular}{|c|c|c|c|}
\hline & Resection $(+)$ & Resection $(-)$ & Total \\
\hline Carcinomas & 7979 & 2158 & 10,137 \\
\hline 1. Squamous cell carcinoma & 7116 & 2021 & 9137 \\
\hline 2. Basaloid(-squamous) carcinoma & 82 & 9 & 91 \\
\hline 3. Carcinosarcoma & 26 & 4 & 30 \\
\hline 4. Adenocarcinoma in the Barrett's esophagus & 346 & 32 & 378 \\
\hline 5. Other adenocarcinoma & 302 & 49 & 351 \\
\hline 6. Adenosquamous carcinoma & 20 & 3 & 23 \\
\hline 7. Mucoepidermoid carcinoma & 5 & 0 & 5 \\
\hline 8. Adenoid cystic carcinoma & 2 & 0 & 2 \\
\hline 9. Endocrine cell carcinoma & 46 & 18 & 64 \\
\hline 10. Undifferentiated carcinoma & 5 & 7 & 12 \\
\hline 11. Others & 29 & 15 & 44 \\
\hline Other malignancies & 42 & 6 & 48 \\
\hline 1. Malignant non-epithelial tumors & 10 & 1 & 11 \\
\hline 2. Malignant melanoma & 25 & 3 & 28 \\
\hline 3. Other malignant tumors & 7 & 2 & 9 \\
\hline Not specified & 127 & 24 & 151 \\
\hline Total & 8148 & 2188 & 10,336 \\
\hline
\end{tabular}

Resection: including endoscopic resection 
Table 38 Malignant esophageal disease (clinical characteristics)

\begin{tabular}{|c|c|c|c|c|c|c|c|}
\hline & \multicolumn{4}{|c|}{ Operation $(+)$} & \multirow[t]{3}{*}{ EMR or ESD } & \multirow[t]{3}{*}{ Operation $(-)$} & \multirow[t]{3}{*}{ Total } \\
\hline & \multirow[t]{2}{*}{ Cases } & \multicolumn{3}{|c|}{ Hospital mortality } & & & \\
\hline & & $\sim 30$ days & 31-90 days & $\begin{array}{l}\text { Total (including } \\
\text { after } 91 \text {-day mortality) }\end{array}$ & & & \\
\hline 1. Esophageal cancer & 6151 & $39(0.6)$ & $72(1.2)$ & $141(2.3)$ & 1955 & 2182 & 10,288 \\
\hline \multicolumn{8}{|l|}{ Location } \\
\hline (1) Cervical esophagus & 203 & $1(0.5)$ & $6(3.0)$ & $13(6.4)$ & 68 & 182 & 453 \\
\hline (2) Thoracic esophagus & 5030 & $31(0.6)$ & $61(1.2)$ & $115(2.3)$ & 1580 & 1737 & 8347 \\
\hline (3) Abdominal esophagus & 651 & $4(0.6)$ & $3(0.5)$ & $7(1.1)$ & 136 & 100 & 887 \\
\hline (4) Multiple cancers & 260 & $3(1.2)$ & $2(0.8)$ & $6(2.3)$ & 136 & 60 & 456 \\
\hline (5) Others/not described & 7 & 0 & 0 & 0 & 35 & 103 & 145 \\
\hline \multicolumn{8}{|l|}{ Tumor depth } \\
\hline (A) Superficial cancer (T1) & 2019 & $10(0.5)$ & $15(0.7)$ & $34(1.7)$ & 1952 & 166 & 4137 \\
\hline Mucosal cancer $(T 1 a)$ & 434 & $4(0.9)$ & $1(0.2)$ & $6(1.4)$ & 1544 & 37 & 2015 \\
\hline (B) Advanced cancer (T2-T4) & 4130 & $29(0.7)$ & $56(1.4)$ & $106(2.6)$ & 3 & 2012 & 6145 \\
\hline (C) Not specified & 2 & 0 & 1 & 1 & 0 & 4 & 6 \\
\hline 2. Multiple primary cancers & 1022 & $8(0.8)$ & $11(1.1)$ & $28(2.7)$ & 490 & 304 & 1816 \\
\hline 1) Synchronous & 583 & $5(0.9)$ & $4(0.7)$ & $15(2.6)$ & 202 & 175 & 960 \\
\hline (1) Head and neck & 164 & 0 & $1(0.6)$ & $3(1.8)$ & 78 & 58 & 300 \\
\hline (2) Stomach & 217 & $2(0.9)$ & $1(0.5)$ & $5(2.3)$ & 71 & 55 & 343 \\
\hline (3) Colorectum & 71 & $1(1.4)$ & $1(1.4)$ & $3(4.2)$ & 14 & 11 & 96 \\
\hline (4) Lung & 26 & 0 & 0 & 0 & 3 & 13 & 42 \\
\hline (5) Pancreas & 5 & 0 & 0 & 0 & 0 & 3 & 8 \\
\hline (6) Liver & 12 & $1(8.3)$ & 0 & $1(8.3)$ & 4 & 1 & 17 \\
\hline (7) Others & 45 & $1(2.2)$ & 0 & $1(2.2)$ & 8 & 17 & 70 \\
\hline (8) Triple cancers & 43 & 0 & $1(2.3)$ & $2(4.7)$ & 22 & 16 & 81 \\
\hline (9) Unknown & 0 & 0 & 0 & 0 & 2 & 1 & 3 \\
\hline 2) Metachronous & 439 & $3(0.7)$ & 7 (1.6) & $13(3.0)$ & 288 & 129 & 856 \\
\hline (1) Head and neck & 81 & 0 & 0 & 0 & 81 & 15 & 177 \\
\hline (2) Stomach & 99 & $2(2.0)$ & $2(2.0)$ & $5(5.1)$ & 69 & 36 & 204 \\
\hline (3) Colorectum & 53 & 0 & $1(1.9)$ & $1(1.9)$ & 24 & 16 & 93 \\
\hline (4) Lung & 23 & 0 & 0 & 0 & 14 & 8 & 45 \\
\hline (5) Pancreas & 2 & 0 & 0 & 0 & 0 & 0 & 2 \\
\hline (6) Liver & 5 & 0 & 0 & 0 & 4 & 3 & 12 \\
\hline (7) Others & 145 & $1(0.7)$ & $3(2.1)$ & $6(4.1)$ & 49 & 31 & 225 \\
\hline (8) Triple cancers & 31 & 0 & $1(3.2)$ & $1(3.2)$ & 47 & 17 & 95 \\
\hline (9) Unknown & 0 & 0 & 0 & 0 & 0 & 3 & 3 \\
\hline Unknown & 0 & 0 & 0 & 0 & 0 & 0 & 0 \\
\hline
\end{tabular}

( ), Mortality \%

$E M R$ endoscopic mucosal resection (including endoscopic submucosal dissection 
Table 39 Malignant esophageal disease (surgical procedures)

\begin{tabular}{|c|c|c|c|c|c|c|c|c|c|}
\hline & \multicolumn{4}{|c|}{ Operation $(+)$} & \multicolumn{4}{|c|}{ Thoracoscopic and/or laparoscopic procedure } & \multirow{3}{*}{$\begin{array}{l}\text { EMR } \\
\text { or } \\
\text { ESD }\end{array}$} \\
\hline & \multirow[t]{2}{*}{ Cases } & \multicolumn{3}{|c|}{ Hospital mortality } & \multirow[t]{2}{*}{ Cases } & \multicolumn{3}{|c|}{ Hospital mortality } & \\
\hline & & $\sim 30$ days & 31-90 days & $\begin{array}{l}\text { Total (including } \\
\text { after } 91 \text {-day } \\
\text { mortality) }\end{array}$ & & $\sim 30$ days & 31-90 days & $\begin{array}{l}\text { Total (including } \\
\text { after } 91 \text {-day } \\
\text { mortality) }\end{array}$ & \\
\hline Superficial cancer $(\mathrm{T} 1)$ & 2019 & $10(0.5)$ & $15(0.7)$ & $34(1.7)$ & 1306 & $4(0.3)$ & $9(0.7)$ & $16(1.2)$ & 1952 \\
\hline Mucosal cancer $(T 1 a)$ & 434 & $4(0.9)$ & $1(0.2)$ & $6(1.4)$ & 260 & $2(0.8)$ & $1(0.4)$ & $3(1.2)$ & 1544 \\
\hline Esophagectomy & 2019 & $10(0.5)$ & $15(0.7)$ & $34(1.7)$ & 1306 & $4(0.3)$ & $9(0.7)$ & $16(1.2)$ & 1952 \\
\hline $\begin{array}{l}\text { (1) Transhiatal } \\
\text { esophagectomy }\end{array}$ & 57 & $1(1.8)$ & $1(1.8)$ & $2(3.5)$ & 15 & 0 & 0 & 0 & \\
\hline $\begin{array}{l}\text { (2) Transthoracic (rt.) } \\
\text { esophagectomy and } \\
\text { reconstruction }\end{array}$ & 1709 & $7(0.4)$ & $12(0.7)$ & $27(1.6)$ & 1194 & $3(0.3)$ & $8(0.7)$ & $14(1.2)$ & \\
\hline $\begin{array}{l}\text { (3) Transthoracic (lt.) } \\
\text { esophagectomy and } \\
\text { reconstruction }\end{array}$ & 27 & 0 & 0 & 0 & 3 & 0 & 0 & 0 & \\
\hline $\begin{array}{l}\text { (4) Cervical esophageal } \\
\text { resection and } \\
\text { reconstruction }\end{array}$ & 31 & $1(3.2)$ & $1(3.2)$ & $2(6.5)$ & 15 & 0 & $1(6.7)$ & $1(6.7)$ & \\
\hline $\begin{array}{l}\text { (5) Two-stage } \\
\text { operation }\end{array}$ & 41 & $1(2.4)$ & 0 & $2(4.9)$ & 23 & $1(4.3)$ & 0 & $1(4.3)$ & \\
\hline (6) Others & 135 & 0 & $1(0.7)$ & $1(0.7)$ & 49 & 0 & 0 & 0 & \\
\hline (7) Not specified & 19 & 0 & 0 & 0 & 7 & 0 & 0 & 0 & \\
\hline \multicolumn{10}{|l|}{ Advanced cancer (T2-T4) } \\
\hline Esophagectomy & 4130 & $29(0.7)$ & $56(1.4)$ & $106(2.6)$ & 1734 & $12(0.7)$ & $25(1.4)$ & $42(2.4)$ & 3 \\
\hline $\begin{array}{l}\text { (1) Transhiatal } \\
\text { esophagectomy }\end{array}$ & 57 & $1(1.8)$ & $1(1.8)$ & $3(5.3)$ & 12 & 0 & 0 & 0 & \\
\hline $\begin{array}{l}\text { (2) Transthoracic (rt.) } \\
\text { esophagectomy and } \\
\text { reconstruction }\end{array}$ & 3500 & $26(0.7)$ & $46(1.3)$ & $85(2.4)$ & 1607 & $11(0.7)$ & $22(1.4)$ & $38(2.4)$ & \\
\hline $\begin{array}{l}\text { (3) Transthoracic (lt.) } \\
\text { esophagectomy and } \\
\text { reconstruction }\end{array}$ & 105 & 0 & 0 & $1(1.0)$ & 12 & 0 & 0 & 0 & \\
\hline $\begin{array}{l}\text { (4) Cervical } \\
\text { esophageal } \\
\text { resection and } \\
\text { reconstruction }\end{array}$ & 137 & 0 & $3(2.2)$ & $8(5.8)$ & 23 & 0 & $2(8.7)$ & $2(8.7)$ & \\
\hline $\begin{array}{l}\text { (5) Two-stage } \\
\text { operation }\end{array}$ & 71 & $1(1.4)$ & $4(5.6)$ & $6(8.5)$ & 16 & 0 & 0 & 0 & \\
\hline $\begin{array}{l}\text { (6) Others/not } \\
\text { specified }\end{array}$ & 206 & $1(0.5)$ & $2(1.0)$ & $3(1.5)$ & 58 & $1(1.7)$ & $1(1.7)$ & $2(3.4)$ & \\
\hline (7) Not specified & 54 & 0 & 0 & 0 & 6 & 0 & 0 & 0 & \\
\hline (Depth not specified) & 2 & 0 & 1 & 1 & 0 & 0 & 0 & 0 & 0 \\
\hline $\begin{array}{l}\text { Combined resection of } \\
\text { other organs }\end{array}$ & 351 & $7(2.0)$ & $4(1.1)$ & $15(4.3)$ & & & & & \\
\hline (1) Aorta & 3 & 0 & 0 & 0 & & & & & \\
\hline (2) Trachea, bronchus & 15 & 0 & 0 & 0 & & & & & \\
\hline (3) Lung & 67 & $3(4.5)$ & 0 & $4(6.0)$ & & & & & \\
\hline (4) Others & 266 & $4(1.5)$ & $4(1.5)$ & $11(4.1)$ & & & & & \\
\hline Unknown & 0 & 0 & 0 & 0 & & & & & \\
\hline Salvage surgery & 264 & $4(1.5)$ & $11(4.2)$ & $21(8.0)$ & 58 & $1(1.7)$ & $1(1.7)$ & $3(5.2)$ & 29 \\
\hline
\end{tabular}




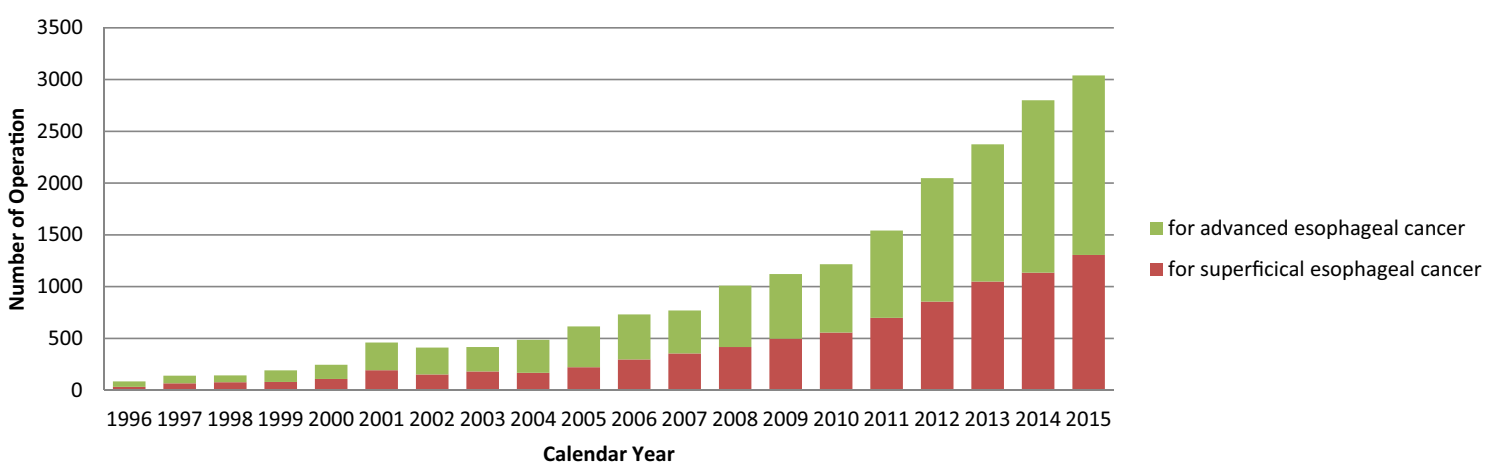

Fig. 4 Annual trend of video-assisted esophagectomy for esophageal malignancy

Table 40 Mortality after combined resection of the neighboring organs

\begin{tabular}{|c|c|c|c|c|c|c|c|c|c|c|c|c|c|c|c|}
\hline \multirow[t]{3}{*}{ Year } & \multirow{2}{*}{\multicolumn{3}{|c|}{ Esophagectomy }} & \multicolumn{12}{|c|}{ Combined resection } \\
\hline & & & & \multicolumn{3}{|c|}{ Aorta } & \multicolumn{3}{|c|}{ Tracheobronchus } & \multicolumn{3}{|l|}{ Lung } & \multicolumn{3}{|c|}{ Others } \\
\hline & $\mathrm{a}$ & $\mathrm{b}$ & c $(\%)$ & $\mathrm{a}$ & b & c $(\%)$ & $\mathrm{a}$ & b & $\mathrm{c}(\%)$ & $\mathrm{a}$ & $\mathrm{b}$ & $\mathrm{c}(\%)$ & $\mathrm{a}$ & $\mathrm{b}$ & c $(\%)$ \\
\hline 1996 & 4194 & 120 & 2.86 & 7 & 3 & 42.86 & 24 & 0 & 0.00 & 50 & 2 & 4.00 & 78 & 4 & 5.13 \\
\hline 1997 & 4441 & 127 & 2.86 & 1 & 0 & 0.00 & 34 & 5 & 14.71 & 56 & 1 & 1.79 & 94 & 3 & 3.19 \\
\hline 1998 & 4878 & 136 & 2.79 & 4 & 0 & 0.00 & 29 & 0 & 0.00 & 74 & 1 & 1.35 & 128 & 2 & 1.56 \\
\hline 1999 & 5015 & 116 & 2.31 & 5 & 0 & 0.00 & 23 & 2 & 8.70 & 68 & 0 & 0.00 & 122 & 1 & 0.82 \\
\hline 2000 & 5350 & 81 & 1.51 & 2 & 0 & 0.00 & 23 & 2 & 8.70 & 69 & 0 & 0.00 & 96 & 1 & 1.04 \\
\hline 2001 & 5521 & 110 & 1.99 & 1 & 0 & 0.00 & 26 & 1 & 3.85 & 83 & 3 & 3.61 & 99 & 2 & 2.02 \\
\hline 2002 & 4904 & 66 & 1.35 & 3 & 1 & 33.33 & 20 & 2 & 10.00 & 63 & 0 & 0.00 & 63 & 1 & 1.59 \\
\hline 2003 & 4639 & 45 & 0.97 & 0 & 0 & 0.00 & 24 & 2 & 8.33 & 58 & 0 & 0.00 & 88 & 1 & 1.14 \\
\hline 2004 & 4739 & 64 & 1.35 & 2 & 0 & 0.00 & 17 & 0 & 0.00 & 59 & 5 & 8.47 & 119 & 2 & 1.68 \\
\hline 2005 & 5163 & 52 & 1.01 & 1 & 0 & 0.00 & 11 & 1 & 9.09 & 67 & 1 & 1.49 & 73 & 1 & 1.37 \\
\hline 2006 & 5236 & 63 & 1.20 & 0 & 0 & 0.00 & 17 & 0 & 0.00 & 62 & 2 & 3.23 & 122 & 3 & 2.46 \\
\hline 2007 & 4990 & 60 & 1.20 & 0 & 0 & 0.00 & 25 & 1 & 4.00 & 44 & 1 & 2.27 & 138 & 2 & 1.45 \\
\hline 2008 & 5124 & 63 & 1.23 & 0 & 0 & 0.00 & 17 & 1 & 5.88 & 48 & 1 & 2.08 & 185 & 0 & 0.00 \\
\hline 2009 & 5260 & 63 & 1.20 & 0 & 0 & 0.00 & 19 & 2 & 10.53 & 58 & 2 & 3.45 & 211 & 3 & 1.42 \\
\hline 2010 & 5180 & 45 & 0.87 & 2 & 0 & 0.00 & 33 & 0 & 0.00 & 58 & 0 & 0.00 & 245 & 5 & 2.04 \\
\hline 2011 & 5430 & 38 & 0.70 & 4 & 0 & 0.00 & 26 & 0 & 0.00 & 41 & 0 & 0.00 & 179 & 5 & 2.79 \\
\hline 2012 & 6055 & 47 & 0.78 & 2 & 0 & 0.00 & 23 & 1 & 4.35 & 69 & 0 & 0.00 & 240 & 1 & 0.42 \\
\hline 2013 & 5824 & 41 & 0.70 & 2 & 0 & 0.00 & 44 & 0 & 0.00 & 77 & 1 & 1.30 & 156 & 3 & 1.92 \\
\hline 2014 & 6244 & 47 & 0.75 & 2 & 0 & 0.00 & 24 & 0 & 0.00 & 77 & 3 & 3.90 & 227 & 3 & 1.32 \\
\hline 2015 & 6151 & 39 & 0.63 & 3 & 0 & 0.00 & 15 & 0 & 0.00 & 67 & 3 & 4.48 & 266 & 4 & 1.50 \\
\hline Total & $1,04,338$ & 1423 & 1.36 & 41 & 4 & 9.76 & 273 & 20 & 7.33 & 1248 & 26 & 2.08 & 2929 & 47 & 1.60 \\
\hline
\end{tabular}

$a$ Number of patients who underwent the operation

$b$ Number of patients died within 30 days after operation

$c \%$ ratio of b/a, i.e., direct operative mortality

cancer, and for 1734 patients (42.0\%) with an advanced cancer. The number of cases of thoracoscopic and/or laparoscopic surgery for superficial or advanced cancer has been increasing for these several years (Fig. 4).

Combined resection of the neighboring organs during resection of an esophageal cancer was performed in 351 patients (Tables 39, 40). Resection of the aorta together with esophagectomy was performed in three cases.
Tracheal and/or bronchial resection combined with esophagectomy was performed in 15 patients, with the both of 30-day mortality rate and the hospital mortality rate at $0 \%$. Lung resection combined with esophagectomy was performed in 67 patients, with the 30-day mortality rate at $4.5 \%$ and the hospital mortality rate at $6.0 \%$.

Salvage surgery after definitive (chemo-)radiotherapy was performed in 264 patients, with the 30-day mortality 
rate at $1.5 \%$ and with the hospital mortality rate at $8.0 \%$ (Table 39).

Lastly, in spite of the efforts of the Committee to cover wider patient populations to this annual survey, the majority of the institutions which responded to the questionnaire were the departments of thoracic or esophageal surgery. It should be noted that larger number of patients with esophageal diseases should have been treated medically and endoscopically. We should continue our effort for complete survey through more active collaboration with the Japan Esophageal Society and other related societies.

Acknowledgements On behalf of The Japanese Association for Thoracic Surgery, the authors thank the Heads of the Affiliate and Satellite Institutes of Thoracic Surgery for their cooperation, and the Councilors of the Japan Esophageal Society.

Open Access This article is distributed under the terms of the Creative Commons Attribution 4.0 International License (http://creative commons.org/licenses/by/4.0/), which permits unrestricted use, distribution, and reproduction in any medium, provided you give appropriate credit to the original author(s) and the source, provide a link to the Creative Commons license, and indicate if changes were made.

\section{References}

1. Masuda M, Okumura M, Doki Y, Endo S, Hirata Y, Kobayashi J, et al. Thoracic and cardiovascular surgery in Japan during 2014annual report by the Japanese Association for Thoracic Surgery. Gen Thorac Cardiovasc Surg. 2016;64:665-97.

2. Ueda $\mathrm{Y}$, Osada $\mathrm{H}$, Osugi $\mathrm{H}$. Thoracic and cardiovascular surgery in Japan during 2005-annual report by the Japanese Association for Thoracic Surgery. Gen Thorac Cardiovasc Surg. 2007;55:377-99.

3. Kuwano H, Amano J, Yokomise H. Thoracic and cardiovascular surgery in Japan during 2010 - annual report by the Japanese Association for Thoracic Surgery. Gen Thorac Cardiovasc Surg. 2012;60:680-708.

4. Kazui T, Osada H, Fujita H. Thoracic and cardiovascular surgery in Japan during 2004 - annual report by the Japanese Association for Thoracic Surgery. Jpn J Thorac Cardiovasc Surg. 2006;54:363-86.

5. Kazui $\mathrm{T}$, Wada $\mathrm{H}$, Fujita $\mathrm{H}$. Thoracic and cardiovascular surgery in Japan during 2003 - annual report by the Japanese Association for Thoracic Surgery. Jpn J Thorac Cardiovasc Surg. 2005;53:517-36.

6. Endo S, Ikeda N, Kondo T, et al. Development of an annually updated Japanese national clinical database for chest surgery in 2014. Gen Thorac Cardiovasc Surg. 2016;64(10):569-76. https:// doi.org/10.1007/s11748-016-0697-1 Epub 2016.

\section{Affiliations}

Committee for Scientific Affairs, The Japanese Association for Thoracic Surgery $\cdot$ Munetaka Masuda ${ }^{2}$. Shunsuke Endo ${ }^{3} \cdot$ Shoji Natsugoe ${ }^{4} \cdot$ Hideyuki Shimizu $^{5} \cdot$ Yuichiro Doki $^{6} \cdot$ Yasutaka Hirata $^{7} \cdot$ Junjiro Kobayashi $^{8}$. Noboru Motomura ${ }^{9} \cdot K_{1 y o h a r u ~ N a k a n o}{ }^{10} \cdot$ Hiroshi Nishida $^{11} \cdot$ Morihito Okada $^{12} \cdot$ Yoshikatsu Saiki $^{13}$. Aya Saito ${ }^{14}$. Yukio Sato ${ }^{1} \cdot$ Kazuo Tanemoto ${ }^{15} \cdot$ Yasushi Toh $^{16} \cdot$ Hiroyuki Tsukihara $^{17} \cdot$ Shinji Wakui $^{18}$. Hiroyasu Yokomise $^{19} \cdot$ Kohei Yokoi $^{20} \cdot$ Yutaka Okita $^{21}$

Munetaka Masuda survey-adm@umin.net

1 Department of Thoracic Surgery, University of Tsukuba, Tsukuba, Japan

2 Department of Surgery, Yokohama City University, Yokohama, Japan

3 Department of Thoracic Surgery, Jichi Medical University, Tochigi, Japan

4 Department of Digestive Surgery and Breast and Thyroid Surgery, Kagoshima University, Kagoshima, Japan

5 Department of Cardiovascular Surgery, Keio University, Tokyo, Japan

6 Department of Gastroenterological Surgery, Osaka University Graduate School of Medicine, Osaka, Japan

7 Department of Cardiac Surgery, The University of Tokyo Hospital, Tokyo, Japan

8 Department of Cardiovascular Surgery, National Cerebral and Cardiovascular Center, Osaka, Japan

9 Department of Cardiovascular Surgery, Toho University, Sakura Medical Center, Chiba, Japan
10 Harajuku Rehabilitation Hospital, Tokyo, Japan

11 Rehabilitation, Tokyo Shinagawa Hospital, Tokyo, Japan

12 Department of Surgical Oncology, Hiroshima University, Higashihiroshima, Japan

13 Division of Cardiovascular Surgery, Tohoku University Graduate School of Medicine, Miyagi, Japan

14 Division of Cardiovascular Surgery, Faculty of Medicine, Sakura Medical Center, Toho University, Tokyo, Japan

15 Department of Cardiovascular Surgery, Kawasaki Medical School, Okayama, Japan

16 Department of Gastroenterological Surgery, National Kyushu Cancer Center, Fukuoka, Japan

17 Department of Cardiothoracic Surgery, Graduate School of Medicine, The University of Tokyo, Tokyo, Japan

18 Nihon University Hospital Cardiovascular Surgery, Tokyo, Japan

19 Department of General Thoracic Surgery, Faculty of Medicine, Kagawa University, Kagawa, Japan

20 Department of Thoracic Surgery, Nagoya University Graduate School of Medicine, Aichi, Japan

21 Cardio-aortic Center, Takatsuki General Hospital, Osaka, Japan 